\author{
Golnoush ZEIDABADI* \\ Seyed Mojtaba MAHMOUDZADEH ${ }^{* *}$ \\ Marziye HEMATI ${ }^{* * *}$
}

\title{
STRATEGIJE DEMARKETINGA U UPRAVLJANJU TURISTIČKOM POTRAŽNJOM: STUDIJA SLUČAJA KASHAN U IRANU
}

\section{DEMARKETING STRATEGIES FOR TOURISM DEMAND MANAGEMENT: CASE STUDY OF KASHAN, IRAN}

\begin{abstract}
SAŽETAK: Ovo istraživanje ima za cilj izmjeriti percepciju razine zagušenja turistima i utvrditi prioritete kod odabira strategije demarketinga u iranskom gradu Kashanu. U ovom primijenjenom istraživanju, nakon pregleda literature i odabira elemenata te dimenzija strategija demarketinga, provedene su ankete sudionika (vodiči, stanovnici, gradske vlasti i znanstvenici u području turizma) i polustrukturirani intervjui. Rezultati pokazuju da je percipirano zagušenje turistima u Kashanu na rubu prihvatnog kapaciteta. Za vlast je čimbenik osoblje najviše rangiran među elementima marketinškog spleta, a slijede ga cijena, promocija, proces, fizički dokaz, proizvod i mjesto. Znanstvenici također smatraju da je osoblje na prvom mjestu, a slijede ga cijena, mjesto, proces, proizvod i fizički dokazi. Na demarketing glavne turističke destinacje Irana, Kashana, čini se da su najveći utjecaj također imali osoblje i kooperativni čimbenik.
\end{abstract}

KLJUČNE RIJEČI: upravljanje potražnjom, demarketing, smanjenje prekomjerne potražnje, marketinški splet, održivi turizam

\begin{abstract}
This study aims to measure the perception of tourist congestion and prioritize demarketing strategies in the city of Kashan. In this applied-survey research, after reviewing the literature and extracting elements and dimensions of demarketing strategies, using a questionnaire and semi-structured interview, the ideas of the participants (tour guides, local people, city authorities, tourism academics) were investigated. The results show that the perceived tourist congestion in Kashan is at its carrying capacity threshold. The authorities deem that 'personnel' factor (among P7s) is ranked at the top, followed by 'price', 'promotion', 'process', 'physical evidence', 'product', and 'place'. The academics also see 'personnel' as most prominent, before 'price', 'place', 'process', 'product', and 'physical evidence'. As for demarketing of Iran's major tourist destination, 'personnel' and cooperative factor seem to different sectors for demand management seemed to have the highest influence on.
\end{abstract}

KEY WORDS: demand management, demarketing, overfull demand reduction, marketing mix, sustainable tourism

* Golnoush Zeidabadi, MA graduate in Tourism Management from Allameh Tabataba'i University, Tehran, Iran, e-mail: g.zeidabadi@gmail.com, ORCID: 0000-0002-8011-1960

** Assistant Professor Seyed Mojtaba Mahmoudzadeh, Ph.D., Allameh Tabataba'i University, Faculty of Management and Accounting, Tehran, Iran, e-mail: sm.mahmoudzadeh@gmail.com, ORCID: 0000-0003-2035-0801

*** Marziye Hemati, MA graduate in Tourism Management from Allameh Tabataba'i University, Tehran, Iran, e-mail: Marziyeh.hemati90@gmail.com, ORCID: 0000-0001-6116-1391 


\section{UVOD}

Interes za pojam održivosti u posljednje je vrijeme sve veći kako među potrošačima tako i u kompanijama, a može se povezati sa značajem pitanja zaštite (Watts, 2018). Budući da marketing utječe na održivu potrošnju, čini se da održivi razvoj nije moguć bez učinkovitog marketinga, a on je orijentiran na upravljanje potražnjom pa može ne samo povećati potražnju, nego ju i promijeniti ili smanjiti (Gallagher, 1994). Turističke aktivnosti neosporno imaju svoje posljedice i utjecaje pa negativne utjecaje treba smanjiti na minimum, a pozitivnima treba pokloniti pozornost (Theobald, 2005:79).

Osnovno pitanje održivosti u turizmu je uspostavljanje ravnoteže između potražnje posjetitelja, potrošnje i sposobnosti turističke destinacije i sustava da osiguraju turističke doživljaje bez umanjivanja prirodnog i društvanog kapitala u destinaciji. Jedna od strategija koje se predlažu posebno za turizam je strategija odrasta. Sa svojim velikim udjelom u održivosti i ekonomskom rastu u sustavu turizma, marketing je posebno usredotočen na smanjenje turističkog rasta i potražnje kako bi osigurao bolju ravnotežu između ponude i potražnje (Hall i Wood, 2021) te posljedično doprinio održivom turizmu.

Nakon uspješne primjene demarketinga posebice u područjima nesocijalnih ponašanja, kao što su zlouporaba droga, prostitucija i krijumčarenje - turistički promotori i istraživači su se prvi opredijelili za ovaj koncept s ciljem ograničavanja učinka turizma na okoliš, a zatim su promotori dodatno profitirali time što su se društveni učinci turizma smanjili (Hall i Wood, 2021).

U tom kontekstu, demarketing se definira kao aktivnosti „kojima se razvija ekskluzivnost u datim rezortima putem pasivnog (a katkad i aktivnog) obeshrabrenja određenih tržišnih segmenata" (Medway, Warnaby i Dharni, 2010:125). Demarketing je snažno

\section{INTRODUCTION}

There has been an increasing interest in the concept of sustainability (in both consumers and companies) recently, and it can be connected to the significance of environmental issues (Watts, 2018). Since marketing plays a key role in achieving sustainable consumption, it can be said that sustainable development will not be possible without effective marketing. Marketing focuses on demand management and works toward not only increasing demand but also changing or reducing it (Gallagher, 1994). Tourism activities have consequences and impacts, and no one can deny them. Negatives impacts should be reduced to the minimum while positive ones should be focused on (Theobald, 2005:79).

The main issue in tourism sustainability is creating balance among visitors' demands, consumption, and the capacity of a tourism destination and system in line with securing tourism experiences without reducing natural and social capital in a destination. Among the strategies that have been presented specifically for tourism is the degrowth strategy. The marketing field, with its major share in sustainability and economic growth in the tourism sector, has paid especial attention to demarketing to reduce development and demand in tourism so that it can create a better balance between supply and demand (Hall and Wood, 2021) and consequently help achieve sustainable tourism.

After successful use of demarketing - especially in the areas of antisocial behaviors such as drug misuse, prostitution, and smuggling - tourism marketers and researchers first opted to this concept to limit the environmental effects of tourism, and then the marketers benefited from the concept in reducing the social effects of tourism (Hall and Wood, 2021).

In this context, demarketing is defined as activities "to develop exclusivity in given 
oruđe za svjesno i aktivno ograničavanje cijelog tržišta ili njegovih dijelova (Beeton i Pinge, 2003). Uvodi se kao jedan od alata kreativnih politika koji se može koristiti za postizanje održivosti u turističkim destinacijama (Beeton i Benfield, 2002). Strategije demarketinga stvaraju mogućnosti za korištenje alata menadžmenta posjetitelja u fazi marketinga (Beeton, 2006). Mnogi su znanstvenici, kao npr. Groff (1998), Beeton (2002), Beeton i Benfield (2002), Wearing, Archer i Beeton (2007), Medway i Warnaby (2008), Medway, Warnaby i Dharni (2010), Sadiki (2012), Nared i Visković (2014), Magalhães et al. (2017), Eliasson i Velasco (2018), Weiler et al. (2018), Kumar i Srivastav (2019), Olokesusi et al. (2019), Drugova, Kim i Jakus (2020) u svojim studijama naglasili korištenje strategija demarketinga u upravljanju potražnjom turista.

Destinacija ovog istraživanja, Kashan, sa svojih 14 međunarodnih, 54 nacionalnih i 96 lokalnih registriranih turističkih znamenitosti oduvijek je bila prepoznatljiva među međunarodnim i domaćim turistima. Posjet gradskim atrakcijama obično se definira kao klasična međunarodna tura i ima važno značenje među raznim vrstama organiziranih putovanja. Međutim, čini se da, s obzirom na drevnu povijest grada i njegovo značenje kao važnog turističkog centra Irana, njegove brojne povijesne, kulturne, religiozne i prirodne atrakcije nisu bile sustavno organizirane za prihvat posjetitelja, što je neophodno za nesmetan i brži održivi razvoj. Podaci Statističkog centra Irana i Organizacije kulturne baštine, rukotvorina i turizma grada Kashana o povijesnim znamenitostima i hotelima ukazuju na razdoblja velike potražnje i pada, što ukazuje na sezonalnost turizma u ovome gradu. Također, na temelju neslužbenih izvješća (turističkih vodiča, turista i lokalnih turističkih eksperata), Kashan je katkada zagušen turistima.

Zbog turističke zagušenosti i njezinih nepoželjnih utjecaja na turizam (Clements, 1989) te zbog globalne opredijeljenosti za resorts through the passive (and sometimes active) discouragement of certain market segments" (Medway, Warnaby and Dharni, 2010:125). Demarketing is a powerful tool of marketing that is used consciously and actively to restrict the whole market or parts of it (Beeton and Pinge, 2003). It is introduced as one of the creative policy tools that can be used to reach sustainability in tourist destinations (Beeton and Benfield, 2002). Demarketing strategies create opportunities to use visitor management tools in the marketing stage (Beeton, 2006). Many studies such as Groff (1998), Beeton (2002), Beeton and Benfield (2002), Wearing, Archer and Beeton (2007), Medway and Warnaby (2008), Medway, Warnaby and Dharni (2010), Sadiki (2012), Nared and Visković (2014), Magalhães et al. (2017), Eliasson and Velasco (2018), Weiler et al. (2018), Kumar and Srivastav (2019), Olokesusi et al. (2019), Drugova, Kim and Jakus (2020) emphasized using demarketing strategies to manage tourist demands.

The destination of the study, Kashan, with 14 internationally, 54 nationally, and 96 provincially registered tourist sites, has always been noticeable for international and national tourists. Visiting the city attractions is usually defined as classic international tours, reserving a significant stance among different tours. However, it seems that considering the ancient history of the city and its stance as a major tourism hub in Iran, its many historical, cultural, religious, and natural attractions have systematically not been organized for tourist visiting, a necessary step for a smoother and quicker sustainable development path. The data from the Statistical Centre of Iran and by Kashan's Cultural Heritage, Handicrafts, and Tourism Organization of Kashan from historical sites and hotels indicate periods of demand climax and recession, showing seasonal tourism industry in this city. Also, based on unofficial reports (by tour guides, tourists, and local tourism experts), Kashan sometimes faces tourist congestion. 
održivi turizam (Gallagher, 1994), ovome gradu potrebno je opće razumijevanje demarketinga u turizmu. Ovo istraživanje ima za cilj prvo istražiti percipiranu razinu zagušenosti, a zatim odrediti redosljed strategija demarketinga za Kashan. Studija će odgovoriti na sljedeća istraživačka pitanja:

1. Koja je percepcija razine zagušenosti u Kashanu?

2. Koje dimenzije i elementi demarketinga grada se temelje na literaturi?

3. Kojim dimenzijama i elementima demarketinga treba dati prvenstvo prilikom upravljanja turističkom potražnjom Kashana?

\section{PREGLED LITERATURE}

\subsection{Demarketing}

Kotler i Levy (1971:75) prvi su uveli termin demarketing definirajući ga kao "aspekt marketinga koji se bavi privremenim ili stalnim obeshrabrivanjem potrošača općenito ili neke posebne kategorije potrošača." Razlozi za odabir strategija demarketinga uključuju održivost destinacije, podjelu tržišta i cilja, smanjenje učinka sezonalnosti i sprječavanje/upravljanje krizom (Medway, Warnaby i Dharni, 2010).

Koncept demarketinga koristi se za smanjenje potražnje u slučaju pretjerane potražnje, a koncept protu-marketinga rabi se u slučaju pojave nezdrave potražnje (Kotler, 1973). Osnovna premisa demarketinga je smanjenje potrošnje proizvoda. Kotler i Levy (1971) definirali su četiri tipa demarketinga: opći demarketing, selektivni demarketing, prividni demarketing i nenamjerni demarketing. Bradly i Blythe (2014) ovoj su klasifikaciji dodali i protu-marketing i marketinšku prilagodbu. Chaudhry, Cesareo i Pastore (2019) također su dodali opće koncepte poput zaštitni demarketing,
Due to tourist congestion and its undesirable consequences on the tourism industry (Clements, 1989) and global determinism to achieve sustainable development (Gallagher, 1994), general understanding of demarketing is necessary for tourism industry in this city. This study aims to first investigate the perceived level of congestion and then prioritize demarketing strategies in Kashan. The following research questions will be answered in this study:

1. What is the perception of the congestion level in Kashan?

2. What are dimensions and elements of demarketing of the city based on the literature?

3. Which demarketing dimensions and elements are the priorities in tourist demand management of Kashan?

\section{LITERATURE REVIEW}

\subsection{Demarketing}

Kotler and Levy (1971:75) originally introduced demarketing and defined it as "that aspect of marketing that deals with discouraging customers in general or a certain class of customers in particular on either a temporary or a permanent basis." The reasons for resorting to a demarketing strategy include destination sustainability, market division and target, reducing seasonality effect, and crisis prevention/management (Medway, Warnaby and Dharni, 2010).

The concept of demarketing is used to reduce demand when facing overfull demand, and the concept of counter-marketing is used when facing unwholesome demand (Kotler, 1973). The basic premise in demarketing involves reducing product consumption. Kotler and Levy (1971) identified four types of demarketing: 'general demarketing', 'selective demarketing', 'ostensible demarketing', and 'unintentional demarketing'. Bradley and Blythe (2014) added 'counter-marketing' and 'marketing adjustment' to this classification. Chaudhry, Cesareo and $\mathrm{Pa}$ store (2019) also added such general concepts as 
preventivni demarketing i borbeni demarketing.

\subsection{Marketinški splet u demarketingu}

Razvoj bilo kakvog marketinškog plana uključuje definiranje ciljeva, rješavanje proračuna, razradu praktičnih planova, praćenje i kontrolu (Magalhães et al., 2017). Glavni strateški marketinški alati obično su bile četiri komponente marketinškog spleta (4P): proizvod, mjesto, cijena i promocija (Azzam, 2019). Drugi su znanstvenici predlagali drugačije klasifikacije marketinškog spleta. Na primjer, Booms i Bitner (1981) dodali su nove komponente: fizički dokaz, ljudi i proces te su predstavili splet od sedam elemenata. Clements (1989) je smatrao da su samo cijena, proizvod i promocija demarketinški alati. Proučavajući klasični marketinški splet, Armstrong i Kern (2011) uzeli su u obzir aktivnosti poput ograničene promocije, smanjenja korištenja pogodnosti, i određenih područja, odsustvo destinacijskog oglašavanja te posebne doživljaje kao demarketinški pristup. Treba naznačiti da ovi pristupi nisu spominjani u literaturi prije 2011. godine. Ipak, literatura strategije demarketinga $u$ turizmu često koristi klasična 4P (Azzam, 2019).

\subsection{Demarketing u turizmu}

Poznato je da nema puno studija na temu demarketinga u turizmu (Beeton i Benfield, 2002; Olokesusi et al., 2019). Istraživanje o demarketingu i turizmu usmjereno je na demarketing i strategije održivog razvoja atrakcija poput nacionalnih parkova i očuvanih resursa (npr., Groff, 1998; Beeton, 2003; Wearing i Archer, 2005; Kern, 2006; Armstrong i Kern, 2011; Whitelaw et al., 2014; Drugova, Kim i Jakus, 2020) ili demarketing u destinacijama s kulturnim atrakcijama (npr., Fullerton, McGettigan i Stephens, 2010; Soliman, 2010; Sadiki, 2012; Peeters et 'protective demarketing', 'preventive demarketing', and 'combative demarketing'.

\subsection{Marketing mix in demarketing}

Developing any marketing plan includes defining aims, settling on the budget, devising practical plans, monitoring, and control (Magalhães et al., 2017). The main strategic marketing tools have traditionally been four in the marketing mix plan, including 'product', 'place', 'price', and 'promotion' (known as the classic 4Ps) (Azzam, 2019). Other scholars presented different classifications of marketing mix. For instance, Booms and Bitner (1981) added the elements of 'physical evidence', 'people', and 'process' and presented a seven-fold mix to this service. Clements (1989) considered only 'price', 'product', and 'promotion' as demarketing tools. Investigate the classic 4Ps, Armstrong and Kern (2011) considered activities such as limited promotion, restriction in using facilities and specific areas, lack of destination advertisement, and specific experiences as demarketing approaches. It should be indicated that these approaches were not present in the literature before 2011. In the demarketing strategy literature of tourism industry, however, the classic 4Ps have often been used (Azzam, 2019).

\subsection{Demarketing in tourism}

It is known that studies focusing on tourism demarketing have been limited (Beeton and Benfield, 2002; Olokesusi et al., 2019). The research about demarketing and tourism have focused on demarketing and sustainable development strategies in attractions such as national parks and preserved resources (see e.g., Groff, 1998; Beeton, 2003; Wearing and Archer, 2005; Kern, 2006; Armstrong and Kern, 2011; Whitelaw et al., 2014; Drugova, Kim and Jakus, 2020) or demarketing in destinations with cultural attractions (see e.g., Fullerton, McGettigan and Stephens, 2010; 
al., 2018; Krajnović, Raguž i Gortan-Carlin, 2020; Murzyn-Kupisz i Hołuj, 2020). Groff (1998) predlaže korištenje demarketinga i $4 \mathrm{P}$ za sprječavanje čestih problema (razaranje, bacanje smeća, pretjerana potražnja) u nacionalnim parkovima. Koristeći tri od 4P (promocija, proizvod i mjesto) u primjeni demarketinga, Beeton i Benfield (2002) naveli su da bi ove aktivnosti mogle voditi $\mathrm{k}$ upravljanju potražnje. Beeton (2002) je istraživala ograničavanje posjetitelja kao načina smanjenja njihovog pretjeranog negativnog utjecaja te se orijentirala na ,promociju“ naglašavajući ulogu prospekata i brošura. Ispitivanjem demarketinških aktivnosti, kao što su naplata ulaznica i parkinga, nepristupačnost, pristojno ponašanje prema stanovnicima, i smanjeno oglašavanje, došla je do zaključka da promocija ima najmanji učinak na strategije demarketinga.

Medway i Warnaby (2008) uveli su različite vrste demarketinga i neobične marketinške strategije kao što su pasivni demarketing mjesta, informacijski demarketing mjesta, iskvaren marketing mjesta i mračni marketing mjesta. Medway, Warnaby i Dharni (2010) navode nekoliko visoko učinkovitih strategija za demarketing: odsustvo promocije, usmjeravanje alternativne destinacije, informacijski demarketing mjesta, ograničavanje pristupa i cjenovni mehanizmi. Zaključili su da se primjenom općeg selektivnog demarketinga (1) strategije demarketinga mogu koristiti istovremeno, (2) predložene strategije mogu poprimiti oblik marketinškog spleta i (3) da je vremenski faktor značajan za strategije demarketinga. Štoviše, demarketing se može koristiti u određenim vremenima (kad se dogodi kriza), u ciklusima (sezonski) ili kontinuirano.

Weiler et al. (2018) postavili su okvir za dizajn predloženih strategija demarketinga u nacionalnim parkovima. Rezultati su pokazali da je mogućnost penjanja na planinu Wollumbin prihvatljiva strategija s gledišta trenutnih posjetitelja koja bi mogla biti učinkovita za ovu regiju u spoju s modificiranim besplatnim do-
Soliman, 2010; Sadiki, 2012; Peeters et al., 2018; Krajnović, Raguž and Gortan-Carlin, 2020; Murzyn-Kupisz and Hołuj, 2020). Groff (1998) suggested using demarketing and 4Ps to prevent common problems (destruction, littering, and overfull demand) in national parks. Beeton and Benfield (2002), using three of the 4Ps (promotion, product, and place) to implement demarketing, expressed that these activities under demarketing could lead to demand management. Beeton (2002) investigated the visitor reduction as a way to reduce excessive negative visitor impacts, and by emphasizing the role of brochure distribution and websites she focused on the 'promotion' component. By examining demarketing activities such as entrance and car park charges, access difficulty, proper behavior toward the residents, and advertisement reduction, she concluded that 'promotion' has the lowest effect among demarketing strategies.

Medway and Warnaby (2008) introduced different types of demarketing as well as unusual strategies in marketing such as 'passive place demarketing', 'informational place demarketing', 'perverse place marketing', and 'dark place marketing'. Medway, Warnaby and Dharni (2010) considered several strategies highly effective for demarketing purposes: lack of promotion, guidance toward an alternative destination, informational place demarketing, access restriction, and pricing mechanisms. Using general and selective demarketing, they concluded that (1) demarketing strategies could be used simultaneously, (2) the proposed strategies could be in the form of marketing mix, and (3) the time factor is significant in demarketing strategies. Demarketing can be used in specific times (when a crisis occurs), in cycles (seasonally), or in permanence.

Weiler et al. (2018) presented a framework to design the proposed strategies for demarketing in national parks. The findings showed that from the current visitors' point of view, access cost to climb Mount Wollumbin was an acceptable strategy which 
življajem. Također, za prijašnje ili potencijalne posjetitelje, izbor alternativnih proizvoda u alternativnim destinacijama učinkovitija je strategija demarketinga. Dakako, ova strategija zahtijeva razvoj i ciljana poboljšanja svih organizacija destinacijskog menadžmenta na lokalnoj, provincijskoj i nacionalnoj razini. Još važnije, svaka demarketinška strategija zahtijeva prihvaćanje svih skupina dionika, a naročito tradicionalnih vlasnika tvrtki. Groff (1998), Beeton (2003), Wearing i Archer (2005), Armstrong i Kern (2011), Wearing et al. (2016) predstavili su popis praktičnih strategija demarketinga nacionalih parkova prema klasičnom modelu marketinškog spleta (4P).

1. Proizvod se odnosi na modifikaciju proizvoda, npr. držanje nekih prostora zatvorenim za posjetitelje, nametanje ograničenja za neke aktivnosti temeljenih na pojase, sezone, ili razdoblja aktivnosti, a koje dozvoljavaju posebne aktivnosti pod nadzorom (npr. turistička agencija ili upravitelj parka trebaju pratiti posjetitelje) i pripremiti sigurne prostore za usmjeravanje kretanja posjetitelja.

2. Mjesto znači uspostavljanje sustava rezervacija, dozvola za ulaz, parkirališta i ograničavanja kampiranja i boravka turista kako bi se osigurao prilaz nekim drugim teško pristupnim zonama te stvorili ili promovirali drugačiji doživljaji na drugim mjestima.

3. Cijena se odnosi na postavljanje viših potrošačkih cijena, uz različito prilagođivanje cijena i planiranje sustava redova kako bi se povećala cijena i vrijeme posjete nekim znamenitostima.

4. Promocija se odnosi na napuštanje ili smanjivanje određene promocije doživljaja, promoviranje i naglašavanje stvaranja ograničenja nekih doživljaja posjetitelja, promoviranje alternativnih uporaba znamenitosti, promociju virtualnih doživljaja, obrazovanja o okolišnim posljedicama pretjeranih posjeta znamenitosti i edukacije novinara i medija o prikladnom ponašanju (citirano u Weiler et al., 2018). could be effective in combination with the modified no-cost experience for this region. Also, for the previous or potential visitors, choosing alternative products in alternative destinations was a more effective demarketing strategy. This strategy, however, requires the development and targeted upgrade throughout destination management organizations at local, provincial, and national levels. More importantly, every demarketing strategy requires acceptance by all stakeholder groups, especially traditional business owners. With reference to Groff (1998), Beeton (2003), Wearing and Archer (2005), Armstrong and Kern (2011), Wearing et al. (2016), they presented a list of practical demarketing strategies of national parks using the classic 4Ps.

1. Product refers to product modification, e.g. keeping some areas closed for the visitors, imposing restriction on some activities based on the zones, seasons, or activity periods, permitting specific supervised activities (e.g., a tour operator or a park driver should accompany the visitors), and preparing safe areas to guide the movement of the visitors.

2. Place refers to establishing reservation systems, entrance permits, car park, and tourist camping and residence limitations to make access to some areas difficult and create or promote alternative experiences in other sites.

3. Price refers to establishing higher consumer costs, creating different pricing, and planning queue systems to increase the cost and time of visiting some sites.

4. Promotion refers to quitting or reducing specific experience promotion, promoting and emphasizing the creation of limitation on some visitor experiences, promoting alternative uses of the site, promoting virtual experiences, educating about environmental consequences of excessive visiting of the site, and educating journalists and media about proper behavior (cited in Weiler et al., 2018). 
Kumar i Srivastav (2019) istraživali su marketnški splet s 10 komponenti (10P) u razvoju održivog turizma na studiji slučaja otoka Andamana i Nicobar otočja. Splet 10P uključuje klasične komponente 4P i sudionike, fizički dokaz, proces, pakiranje, planiranje i participaciju.

U svom istraživanju o literaturi demarketinga u turizmu Olokesusi et al. (2019) pokazali su da su najobičniji logični razlozi za demarketing u turizmu: (1) očuvanje okolišnog integriteta regulacijom pretrpane potražnje tako da se posjetitelje obeshrabruje u njihovim željama da posjete osjetljiva područja kao što su nacionalni parkovi i (2) smanjenje društveno neprihvatljivih ponašanja, kao npr. nedolično ponašanje, veća zaštita prirodnih resursa. Krajnović, Raguž i Gortan-Carlin (2020) proučavale su kriterije mjerenja sustava menadžmenta kulturnih mjesta u dvije turističke destinacije u Hrvatskoj i zaključile da je demarketing važan sektor strateškog menadžmenta u dvije destinacije u Hrvatskoj. Proučavajući 5 nacionalnih parkova u južnom dijelu Utaha, Drugova, Kim i Jakus (2020) zaključili su da su uprave ovih parkova, zbog zagušenja potražnje, osmislile novu visokokvalitetnu demarketinšku kampanju kako bi se popravio doživljaj posjetitelja i planirale turističke rute do alternativnih destinacija.

Temeljem istraživačkog cilja ove studije spomenutih sedam komponenti marketinškog spleta, uključujući i klasične četiri (cijena, proizvod, mjesto i promocija) (Clements, 1998; Groff, 1998 citirano u Weiler et al., 2018; Beeton, 2003; Kern, 2006; Armstrong i Kern, 2011; Wearing, Schweinsberg i Tower, 2016; Azzam, 2019; Kumar i Srivastav, 2019; Othman et al., 2019; Kwok, Tang i Yu, 2020; Pandey, Ritthichairoek i Puntien, 2020), osoblje, proces (Booms i Bitner, 1981; Kumar i Srivastav, 2019; Othman et al., 2019; Kwok, Tang i Yu, 2020; Pandey, Ritthichairoek i Puntien, 2020), i fizički dokaz (Booms i Bitner, 1981; Kumar i Srivastav, 2019; Othman et al., 2019; Kwok, Tang i Yu, 2020;
Kumar and Srivastav (2019) investigated the 10Ps of marketing in developing sustainable tourism through the case study on the Andaman and Nicobar Islands. The 10Ps include the classic 4Ps alongside 'participants', 'physical evidence', 'process', 'packaging', 'planning', and 'participation'.

Olokesusi et al. (2019) in their study on investigating the demarketing literature in tourism showed that the most common logical reasons for demarketing in tourism are (1) preserving environmental integrity by regulating overfull demand through discouraging the visitors interested in visiting sensitive areas such as national parks, and (2) reducing socially unacceptable behaviors such as misbehaviors in destinations, higher preserving of natural resources. To discover the measurement criteria of the management system of cultural places in two tourist destinations in Croatia, a study by Krajnović, Raguž and Gortan-Carlin (2020) concluded that demarketing is an important sector of strategic management of both destinations. Drugova, Kim and Jakus (2020), studying 5 national parks of southern Utah, concluded that facing demand congestion, the management of these parks devised a new high-quality demarketing campaign to improve the visitor experience and to create visitor routes to alternative destinations.

Based on the research aim, in this study, the perceived 7Ps of marketing, including the classic 4Ps (price, product, place, promotion) (Clements, 1998; Groff, 1998 cited in Weiler et al., 2018; Beeton, 2003; Kern, 2006; Armstrong and Kern, 2011; Wearing, Schweinsberg and Tower, 2016; Azzam, 2019; Kumar and Srivastav, 2019; Othman et al., 2019; Kwok, Tang and Yu, 2020; Pandey, Ritthichairoek and Puntien, 2020), 'personnel', 'process' (Booms and Bitner, 1981; Kumar and Srivastav, 2019; Othman et al., 2019; Kwok, Tang and Yu, 2020; Pandey, Ritthichairoek and Puntien, 2020), and 'physical evidence' (Booms and Bitner, 1981; Kumar and Srivastav, 2019; Othman et al., 2019; Kwok, Tang and Yu, 2020; Pand- 
Pandey, Ritthichairoek i Puntien, 2020), korištene su kao strategije demarketinga za proučavanje destinacije Kashan. Tablica 1 prikazuje dimenzije i elemente marketinških strategija koji su prikupljeni tijekom pregleda literature. Temeljem tih strategija istraživači su odabrali prioritetne strategije demarketinga u destinaciji.

Nakon pregleda literature, određene su dimenzije i elementi demarketinga te su poslani skupini stručnjaka koja se sastojala od 10 eksperata u području marketinga te aktivnih sveučilišnih nastavnika u to vrijeme. Njihova pisana mišljenja pokazala su da je većina njih dodala demarketingu još neke elemente. Ti su elementi pridodani u tablicu dimenzija i elemenata demarketinga te su ponovno poslani stručnjacima na odobrenje konačne Tablice 1 i Slike 1. ey, Ritthichairoek and Puntien, 2020) were used as demarketing strategies in the study destination, Kashan. Based on the literature, dimensions, and elements of demarketing strategies were also collected, shown in Table 1. Based on these strategies, the researchers prioritized the demarketing strategies in the tourism destination.

After reviewing the literature, the dimensions and elements of demarketing were recognized and submitted to the expert panel, who were 10 tourism marketing field experts and were active university lecturers at that time. Their documented opinions showed that the majority of them added some elements to demarketing. These elements were added to the dimensions and elements of the demarketing table and submitted to the experts for the second time; the experts' opinion approved the table this time (Table 1 and Figure 1).

Tablica 1: Teorijski temelj studije koji su sakupili istraživači

\begin{tabular}{|c|c|c|}
\hline $\begin{array}{c}\text { Dimenzije } \\
\text { strategija } \\
\text { demarketinga }\end{array}$ & Elementi strategija demarketinga & Teoretska pozadina \\
\hline \multirow{7}{*}{ Proizvod } & $\begin{array}{l}\text { Odabir iz paketa usluga (popularne } \\
\text { zajedno s nepopularnima) }\end{array}$ & Kotler i Levy (1971) \\
\hline & Pružanje usluga niske razine & $\begin{array}{l}\text { Benfield (2000), Beeton (2006), Kern } \\
\text { (2006), Armstrong i Kern (2011), Weiler et } \\
\text { al. (2018) }\end{array}$ \\
\hline & $\begin{array}{l}\text { Uskraćivanje pogodnosti koje vode } \mathrm{k} \\
\text { nepovoljnoj tržišnoj apsorpciji }\end{array}$ & Kern (2006), Armstrong i Kern (2011) \\
\hline & $\begin{array}{l}\text { Ograničenje dozvola posjeta } \\
\text { (ograničena lokacija) }\end{array}$ & $\begin{array}{l}\text { Beeton (2003), Beeton (2006), Kern } \\
\text { (2006), Armstrong i Kern (2011), Weiler } \text { et } \\
\text { al. (2018) }\end{array}$ \\
\hline & $\begin{array}{l}\text { Smanjenje kvalitete pruženih usluga i } \\
\text { proizvoda }\end{array}$ & $\begin{array}{l}\text { Kotler i Levy (1971), Benfield (2000), } \\
\text { Beeton i Benfield (2002), Beeton i Pinge } \\
\text { (2003), Beeton (2006) }\end{array}$ \\
\hline & $\begin{array}{l}\text { Pružanje informacija posjetiteljima o } \\
\text { zagušenju svih znamenitosti u svako } \\
\text { vrijeme (npr. web stranice) }\end{array}$ & UNWTO (2007), Weiler et al. (2018) \\
\hline & $\begin{array}{l}\text { Planiranje aranžmana prema visokoj } \\
\text { sezoni i punim rezervacijama }\end{array}$ & Mišljenja turističkih eksperata \\
\hline
\end{tabular}




\begin{tabular}{|c|c|c|}
\hline $\begin{array}{c}\text { Dimenzije } \\
\text { strategija } \\
\text { demarketinga }\end{array}$ & Elementi strategija demarketinga & Teoretska pozadina \\
\hline \multirow{4}{*}{ Osoblje } & $\begin{array}{l}\text { Suradnja među različitim sektorima } \\
\text { za upravljanje potražnjom }\end{array}$ & UNWTO (2007) \\
\hline & $\begin{array}{l}\text { Edukacija osoblja i djelatnika u } \\
\text { korištenju predloženih strategija }\end{array}$ & Baum i Lundtorp (2001) \\
\hline & $\begin{array}{l}\text { Zapošljavanje kvalificiranih radnika } \\
\text { za upravljanje vremenom i ponašanje } \\
\text { posjetitelja }\end{array}$ & Baum i Lundtorp (2001) \\
\hline & $\begin{array}{l}\text { Zapošljavanje radnika na pola radnog } \\
\text { vremena (prema sezonama) }\end{array}$ & UNWTO (2007) \\
\hline \multirow{7}{*}{ Cijena } & $\begin{array}{l}\text { Naplaćivanje posjetiteljima za usluge } \\
\text { koje su besplatne izvan sezone }\end{array}$ & $\begin{array}{l}\text { Temeljeno na mišljenjima turističkih } \\
\text { eksperata }\end{array}$ \\
\hline & Povećanje cijena ulaznica & $\begin{array}{l}\text { Kotler i Levy (1971), Dadzie (1989), } \\
\text { Gerstner, Hess i Chu (1993), Clements } \\
\text { (1998), Groff (1998), Wearing i Neil (1999), } \\
\text { Benfield (2001), Beeton (2001), Beeton i } \\
\text { Benfield (2002), McLean, Havitz i Adkins } \\
\text { (2002), Beeton i Pinge (2003), Beeton } \\
\text { (2006), Kern (2006), Wearing, Archer i } \\
\text { Beeton (2007), Medway, Warnaby i Dharni } \\
\text { (2010) Armstrong i Kern (2011), Suh, Rho i } \\
\text { Greene (2012), Weiler } \text { et al. (2018) } \\
\end{array}$ \\
\hline & $\begin{array}{l}\text { Naplaćivanje dodatnih pogodnosti } \\
\text { posjetiteljima }\end{array}$ & $\begin{array}{l}\text { Groff (1998), Benfield (2000), Beeton } \\
\text { (2001), McLean, Havitz i Adkins (2002), } \\
\text { Beeton i Pinge (2003), Beeton (2006), } \\
\text { Kern (2006), Armstrong i Kern (2011), } \\
\text { Suh, Rho i Greene (2011) }\end{array}$ \\
\hline & Ne pružanje sniženja i popusta & $\begin{array}{l}\text { Kotler i Levy (1971), Clements (1998), } \\
\text { Benfield (2000), Beeton i Benfield (2002), } \\
\text { Beeton i Pinge (2003), Beeton (2006), } \\
\text { Kern (2006), Sadiki (2012) }\end{array}$ \\
\hline & Ponuda različitih cijena & $\begin{array}{l}\text { Kern (2006), Armstrong i Kern (2011), } \\
\text { Weiler et al. (2018) }\end{array}$ \\
\hline & Uporaba sustava diskriminacije cijena & UNWTO (2007) \\
\hline & Nalaženje posjetitelja & UNWTO (2007) \\
\hline \multirow{4}{*}{ Distribucija } & $\begin{array}{l}\text { Tiskanje karata s datumom isteka } \\
\text { roka trajanja }\end{array}$ & $\begin{array}{l}\text { Kern (2006), UNWTO (2007), Medway, } \\
\text { Warnaby i Dharni (2010), Armstrong i } \\
\text { Kern (2011) } \\
\end{array}$ \\
\hline & Skraćivanje sati posjete & McLean, Havitz i Adkins (2002) \\
\hline & $\begin{array}{l}\text { Otežani pristup osjetljivim } \\
\text { područjima i popularnim } \\
\text { znamenitostima }\end{array}$ & $\begin{array}{l}\text { Beeton (2003), Beeton (2006), Kern (2006), } \\
\text { UNWTO (2007), Medway, Warnaby i } \\
\text { Dharni (2010), Fullerton, McGettigan i } \\
\text { Stephens (2010), Sadiki (2012), Suh, Rho i } \\
\text { Greene (2012), Weiler et al. (2018) }\end{array}$ \\
\hline & Smanjenje broja distribucijskih luka & $\begin{array}{l}\text { Kotler i Levy (1971), Benfield (2000), } \\
\text { Beeton i Benfield (2002), Beeton i Pinge } \\
\text { (2003), Beeton (2006), Suh, Rho i Greene } \\
\text { (2012), Dadzie (1989), Weiler } \text { et al. (2018) }\end{array}$ \\
\hline
\end{tabular}




\begin{tabular}{|c|c|c|}
\hline $\begin{array}{c}\text { Dimenzije } \\
\text { strategija } \\
\text { demarketinga }\end{array}$ & Elementi strategija demarketinga & Teoretska pozadina \\
\hline \multirow{9}{*}{ Promocija } & $\begin{array}{l}\text { Dijeljenje brošura kojima se upravlja } \\
\text { posjetama te najavljuju vremena i } \\
\text { razdoblja zagušenja posjeta }\end{array}$ & Sadiki (2012) \\
\hline & Prekid oglašavanja & $\begin{array}{l}\text { Kotler i Levy (1971), Dadzie (1989), Groff } \\
\text { (1998), Beeton (2001), Beeton i Benfield } \\
\text { (2002), McLean, Havitz i Adkins (2002), } \\
\text { Beeton i Pinge (2003), Medway, Warnaby i } \\
\text { Dharni (2010), Kern (2006), Sadiki (2012), } \\
\text { Armstrong i Kern (2011) }\end{array}$ \\
\hline & $\begin{array}{l}\text { Prekid marketinga za određenu } \\
\text { znamenitost }\end{array}$ & $\begin{array}{l}\text { Groff (1998), Kern (2006), Armstrong i } \\
\text { Kern (2011), Weiler et al. (2018) } \\
\end{array}$ \\
\hline & $\begin{array}{l}\text { Informiranje posjetitelja o } \\
\text { ograničenjima i problemima vezanima } \\
\text { za njihove posjete }\end{array}$ & $\begin{array}{l}\text { Beeton (2001), Beeton (2003), Beeton } \\
\text { i Pinge (2003), Beeton (2006), Kern } \\
\text { (2006), Wearing, Archer i Beeton (2007), } \\
\text { Armstrong i Kern (2011), Suh, Rho i } \\
\text { Greene (2011) }\end{array}$ \\
\hline & $\begin{array}{l}\text { Oglašavanje / naglašavanje učinaka } \\
\text { pravilnog ponašanja }\end{array}$ & $\begin{array}{l}\text { Dadzie (1989), Benfield (2000), Beeton } \\
\text { (2001), Beeton i Pinge (2003), Beeton } \\
\text { (2006), Kern (2006), UNWTO (2007), } \\
\text { Wearing, Archer i Beeton (2007), } \\
\text { Fullerton, McGettigan i Stephens (2010), } \\
\text { Medway, Warnaby i Dharni (2010), } \\
\text { Armstrong i Kern (2011), Sadiki (2012), } \\
\text { Weiler et al. (2018) }\end{array}$ \\
\hline & $\begin{array}{l}\text { Obeshrabljivanje nepovoljnih } \\
\text { segmenata tržišta oglašavanjem }\end{array}$ & $\begin{array}{l}\text { Gerstner, Hess i Chu (1993), Clements } \\
\text { (1998), Beeton (2001), Beeton i Pinge } \\
\text { (2003), Beeton (2006), Kern (2006), } \\
\text { Fullerton, McGettigan i Stephens (2010), } \\
\text { Armstrong i Kern (2011), Sadiki (2012) }\end{array}$ \\
\hline & $\begin{array}{l}\text { Educiranje masovnih medija o } \\
\text { prikladnim ponašanjima }\end{array}$ & $\begin{array}{l}\text { Beeton (2001), Beeton i Pinge (2003), } \\
\text { Beeton (2006), Weiler et al. (2018) }\end{array}$ \\
\hline & $\begin{array}{l}\text { Ograničavanje glavne promotivne } \\
\text { strategije na odabrane medije kako bi } \\
\text { se privukla željena tržišta i segmenti }\end{array}$ & Wearing, Archer i Beeton (2007) \\
\hline & $\begin{array}{l}\text { Uvođenje drugih desitnacija kao } \\
\text { alternativnih destinacija }\end{array}$ & $\begin{array}{l}\text { Beeton (2006), UNWTO (2007), Wearing, } \\
\text { Archer i Beeton (2007), Fullerton, } \\
\text { McGettigan i Stephens (2010), Medway, } \\
\text { Warnaby i Dharni (2010), Sadiki (2012), } \\
\text { Suh, Rho i Greene (2012) }\end{array}$ \\
\hline \multirow{3}{*}{ Proces } & Ponuda virtualnih tura & $\begin{array}{l}\text { Benfield (2000), Beeton (2006), Weiler et } \\
\text { al. (2018) }\end{array}$ \\
\hline & Ponuda sustava rezervacija & $\begin{array}{l}\text { Kern (2006), Medway, Warnaby i Dharni } \\
\text { (2010), Armstrong i Kern (2011) }\end{array}$ \\
\hline & $\begin{array}{l}\text { Obaveza pokazivanja Dozvola za } \\
\text { posjet znamenitostima }\end{array}$ & $\begin{array}{l}\text { Kern (2006), UNWTO (2007), Fullerton, } \\
\text { McGettigan i Stephens (2010), Armstrong } \\
\text { i Kern (2011), Weiler } \text { et al. (2018) }\end{array}$ \\
\hline
\end{tabular}




\begin{tabular}{|c|c|c|}
\hline $\begin{array}{l}\text { Dimenzije } \\
\text { strategija } \\
\text { demarketinga }\end{array}$ & Elementi strategija demarketinga & Teoretska pozadina \\
\hline \multirow{3}{*}{ Proces } & $\begin{array}{l}\text { Primjena principa prvenstva posjete } \\
\text { prema kapacitetu nosivosti destinacija }\end{array}$ & $\begin{array}{l}\text { Groff (1998), Kern (2006), Armstrong i } \\
\text { Kern (2011) }\end{array}$ \\
\hline & $\begin{array}{l}\text { Posjeta određenih znamenitosti } \\
\text { samo pod nadzorom educiranog ili } \\
\text { podučenog osoblja }\end{array}$ & $\begin{array}{l}\text { Beeton (2006), Kern (2006), Armstrong i } \\
\text { Kern (2011) }\end{array}$ \\
\hline & $\begin{array}{l}\text { Usporeno pružanje usluga kojim se } \\
\text { posjetiteljima produžuje vrijeme i } \\
\text { povećava oportunitetni trošak (kao } \\
\text { npr. čekanje u redu) }\end{array}$ & $\begin{array}{l}\text { Wearing i Neil (1999), Benfield (2000), } \\
\text { Beeton i Benfield (2002), Beeton (2006), } \\
\text { Kern (2006), Wearing, Archer i Beeton } \\
\text { (2007), Armstrong i Kern (2011), Weiler et } \\
\text { al. (2018) }\end{array}$ \\
\hline \multirow{3}{*}{ Fizički dokaz } & $\begin{array}{l}\text { Otvaranje puteva koji turiste vode na } \\
\text { skraćenu posjetu }\end{array}$ & UNWTO (2007), Weiler et al. (2018) \\
\hline & $\begin{array}{l}\text { Postavljanje znakova i ploča kao } \\
\text { putokaza turistima }\end{array}$ & UNWTO (2007) \\
\hline & $\begin{array}{l}\text { Korištenje uniformi za razlikovanje } \\
\text { djelatnika različitih odjela kako bi se } \\
\text { ubrzao protok posjetitelja }\end{array}$ & Mišljenja turističkih eksperata \\
\hline
\end{tabular}

Table 1: The theoretical basis of the study; collected by the researchers

\begin{tabular}{|c|c|c|}
\hline $\begin{array}{l}\text { Dimensions of } \\
\text { demarketing } \\
\text { strategies }\end{array}$ & Elements of demarketing strategies & Theoretical background \\
\hline \multirow{7}{*}{ Product } & $\begin{array}{l}\text { Choosing from service packages } \\
\text { (popular along with unpopular) }\end{array}$ & Kotler and Levy (1971) \\
\hline & Offering low-level services & $\begin{array}{l}\text { Benfield (2000), Beeton (2006), Kern } \\
\text { (2006), Armstrong and Kern (2011), } \\
\text { Weiler } \text { et al. (2018) }\end{array}$ \\
\hline & $\begin{array}{l}\text { Not providing facilities that lead to } \\
\text { unfavorable market absorption }\end{array}$ & Kern (2006), Armstrong and Kern (2011) \\
\hline & $\begin{array}{l}\text { Limited visit permission (Restricted } \\
\text { location) }\end{array}$ & $\begin{array}{l}\text { Beeton (2003), Beeton (2006), Kern } \\
\text { (2006), Armstrong and Kern (2011), } \\
\text { Weiler et al. (2018) }\end{array}$ \\
\hline & $\begin{array}{l}\text { Reduce the quality of services and } \\
\text { products provided }\end{array}$ & $\begin{array}{l}\text { Kotler and Levy (1971), Benfield (2000), } \\
\text { Beeton and Benfield (2002), Beeton and } \\
\text { Pinge (2003), Beeton (2006) }\end{array}$ \\
\hline & $\begin{array}{l}\text { Providing information about } \\
\text { congestion of any site at any time for } \\
\text { visitors (eg websites) }\end{array}$ & UNWTO (2007), Weiler et al. (2018) \\
\hline & $\begin{array}{l}\text { Preparing packages by the } \\
\text { organizations according to high- } \\
\text { seasons and full reservations }\end{array}$ & From the opinions of tourism experts \\
\hline
\end{tabular}




\begin{tabular}{|c|c|c|}
\hline $\begin{array}{l}\text { Dimensions of } \\
\text { demarketing } \\
\text { strategies }\end{array}$ & Elements of demarketing strategies & Theoretical background \\
\hline \multirow{4}{*}{ Personnel } & $\begin{array}{l}\text { Cooperation among different sectors } \\
\text { to manage demands }\end{array}$ & UNWTO (2007) \\
\hline & $\begin{array}{l}\text { Training personnel and staff to use } \\
\text { proposed strategies }\end{array}$ & Baum and Lundtorp (2001) \\
\hline & $\begin{array}{l}\text { Hire skillful workers to manage time } \\
\text { and visitor behavior }\end{array}$ & Baum and Lundtorp (2001) \\
\hline & $\begin{array}{l}\text { Hire part-time workers (based on } \\
\text { seasons) }\end{array}$ & UNWTO (2007) \\
\hline \multirow{7}{*}{ Price } & $\begin{array}{l}\text { Charging visitors for services that are } \\
\text { free through off-peak seasons }\end{array}$ & Based on the opinion of tourism experts \\
\hline & Increase the entrance fees & $\begin{array}{l}\text { Kotler and Levy (1971), Dadzie (1989), } \\
\text { Gerstner, Hess and Chu (1993), Clements } \\
\text { (1998), Groff (1998), Wearing and Neil } \\
\text { (1999), Benfield (2001), Beeton (2001), } \\
\text { Beeton and Benfield (2002), McLean, } \\
\text { Havitz and Adkins (2002), Beeton and } \\
\text { Pinge (2003), Beeton (2006), Kern (2006), } \\
\text { Wearing, Archer and Beeton (2007), } \\
\text { Medway, Warnaby and Dharni (2010), } \\
\text { Armstrong and Kern (2011), Suh, Rho and } \\
\text { Greene (2012), Weiler } \text { et al. (2018) } \\
\end{array}$ \\
\hline & $\begin{array}{l}\text { Charging visitors for additional } \\
\text { facilities }\end{array}$ & $\begin{array}{l}\text { Groff (1998), Benfield (2000), Beeton } \\
\text { (2001), McLean, Havitz and Adkins } \\
\text { (2002), Beeton and Pinge (2003), Beeton } \\
\text { (2006), Kern (2006), Armstrong and Kern } \\
\text { (2011), Suh, Rho and Greene (2011) }\end{array}$ \\
\hline & Offering no undercut and discount & $\begin{array}{l}\text { Kotler and Levy (1971), Clements (1998), } \\
\text { Benfield (2000), Beeton and Benfield } \\
(2002), \text { Beeton and Pinge (2003), Beeton } \\
\text { (2006), Kern (2006), Sadiki (2012) }\end{array}$ \\
\hline & Offering different prices & $\begin{array}{l}\text { Kern (2006), Armstrong and Kern (2011), } \\
\text { Weiler et al. (2018) }\end{array}$ \\
\hline & Using the price discrimination system & UNWTO (2007) \\
\hline & Finding visitors & UNWTO (2007) \\
\hline \multirow[b]{3}{*}{ Distribution } & Providing tickets with expire date & $\begin{array}{l}\text { Kern (2006), UNWTO (2007), Medway, } \\
\text { Warnaby and Dharni (2010), Armstrong } \\
\text { and Kern (2011) }\end{array}$ \\
\hline & Reduce visit hours & McLean, Havitz and Adkins (2002) \\
\hline & $\begin{array}{l}\text { Difficulty accessing sensitive areas } \\
\text { and popular sites }\end{array}$ & $\begin{array}{l}\text { Beeton (2003), Beeton (2006), Kern } \\
\text { (2006), UNWTO (2007), Medway, } \\
\text { Warnaby and Dharni (2010), Fullerton, } \\
\text { McGettigan and Stephens (2010), Sadiki } \\
\text { (2012), Suh, Rho and Greene (2012), } \\
\text { Weiler } \text { et al. (2018) }\end{array}$ \\
\hline
\end{tabular}




\begin{tabular}{|c|c|c|}
\hline $\begin{array}{l}\text { Dimensions of } \\
\text { demarketing } \\
\text { strategies }\end{array}$ & Elements of demarketing strategies & Theoretical background \\
\hline Distribution & $\begin{array}{l}\text { Reducing the number of distribution } \\
\text { ports }\end{array}$ & $\begin{array}{l}\text { Kotler i Levy (1971), Benfield (2000), } \\
\text { Beeton and Benfield (2002), Beeton and } \\
\text { Pinge (2003), Beeton (2006), Suh, Rho and } \\
\text { Greene (2012), Dadzie (1989), Weiler } \text { et al. } \\
\text { (2018) }\end{array}$ \\
\hline \multirow{9}{*}{ Promotion } & $\begin{array}{l}\text { Giving brochures at the entrances to } \\
\text { guide and manage visits along with } \\
\text { announcing hours and seasons of } \\
\text { congestion }\end{array}$ & Sadiki (2012) \\
\hline & Stop advertising & $\begin{array}{l}\text { Kotler and Levy (1971), Dadzie (1989), } \\
\text { Groff (1998), Beeton (2001), Beeton and } \\
\text { Benfield (2002), McLean, Havitz and } \\
\text { Adkins (2002), Beeton and Pinge (2003), } \\
\text { Medway, Warnaby and Dharni (2010), } \\
\text { Kern (2006), Sadiki (2012), Armstrong } \\
\text { and Kern (2011) }\end{array}$ \\
\hline & Stop marketing for a specific site & $\begin{array}{l}\text { Groff (1998), Kern (2006), Armstrong and } \\
\text { Kern (2011), Weiler et al. (2018) }\end{array}$ \\
\hline & $\begin{array}{l}\text { Informing people about the } \\
\text { limitations and problems of their } \\
\text { visits }\end{array}$ & $\begin{array}{l}\text { Beeton (2001), Beeton (2003), Beeton and } \\
\text { Pinge (2003), Beeton (2006), Kern (2006), } \\
\text { Wearing, Archer and Beeton (2007), } \\
\text { Armstrong and Kern (2011), Suh, Rho and } \\
\text { Greene (2011) }\end{array}$ \\
\hline & $\begin{array}{l}\text { Advertising / emphasizing the effects } \\
\text { of appropriate behaviors }\end{array}$ & $\begin{array}{l}\text { Dadzie (1989), Benfield (2000), Beeton } \\
\text { (2001), Beeton and Pinge (2003), Beeton } \\
\text { (2006), Kern (2006), UNWTO (2007), } \\
\text { Wearing, Archer and Beeton (2007), } \\
\text { Fullerton, McGettigan and Stephens } \\
\text { (2010), Medway, Warnaby and Dharni } \\
\text { (2010), Armstrong and Kern (2011), Sadiki } \\
\text { (2012), Weiler } \text { et al. (2018) }\end{array}$ \\
\hline & $\begin{array}{l}\text { Discouraging the unfavorable market } \\
\text { segment by advertising }\end{array}$ & $\begin{array}{l}\text { Gerstner, Hess and Chu (1993), Clements } \\
\text { (1998), Beeton (2001), Beeton and Pinge } \\
\text { (2003), Beeton (2006), Kern (2006), } \\
\text { Fullerton, McGettigan and Stephens } \\
\text { (2010), Armstrong and Kern (2011), Sadiki } \\
\text { (2012) }\end{array}$ \\
\hline & $\begin{array}{l}\text { Educating mass media of appropriate } \\
\text { behaviors }\end{array}$ & \begin{tabular}{|l} 
Beeton (2001), Beeton and Pinge (2003), \\
Beeton (2006), Weiler et al. (2018) \\
\end{tabular} \\
\hline & $\begin{array}{l}\text { Limiting the main promotion strategy } \\
\text { to selected media to attract the } \\
\text { desired markets and segments }\end{array}$ & Wearing, Archer and Beeton (2007) \\
\hline & $\begin{array}{l}\text { Introducing other destinations as } \\
\text { alternative destinations }\end{array}$ & $\begin{array}{l}\text { Beeton (2006), UNWTO (2007), Wearing, } \\
\text { Archer and Beeton (2007), Fullerton, } \\
\text { McGettigan and Stephens (2010), Medway, } \\
\text { Warnaby and Dharni (2010), Sadiki (2012), } \\
\text { Suh, Rho and Greene (2012) }\end{array}$ \\
\hline
\end{tabular}




\begin{tabular}{|c|c|c|}
\hline $\begin{array}{l}\text { Dimensions of } \\
\text { demarketing } \\
\text { strategies }\end{array}$ & Elements of demarketing strategies & Theoretical background \\
\hline \multirow{6}{*}{ Process } & Offering virtual tours & $\begin{array}{l}\text { Benfield (2000), Beeton (2006), Weiler } \text { et } \\
\text { al. (2018) }\end{array}$ \\
\hline & Offering reservation systems & $\begin{array}{l}\text { Kern (2006), Medway, Warnaby and } \\
\text { Dharni (2010), Armstrong and Kern (2011) }\end{array}$ \\
\hline & $\begin{array}{l}\text { The need to provide permissions to } \\
\text { visit the sites }\end{array}$ & $\begin{array}{l}\text { Kern (2006), UNWTO (2007), Fullerton, } \\
\text { McGettigan and Stephens (2010), } \\
\text { Armstrong and Kern (2011), Weiler et al. } \\
(2018)\end{array}$ \\
\hline & $\begin{array}{l}\text { Using the first-come-first-visit system } \\
\text { according to the bearing capacity of } \\
\text { destinations }\end{array}$ & $\begin{array}{l}\text { Groff (1998), Kern (2006), Armstrong and } \\
\text { Kern (2011) }\end{array}$ \\
\hline & $\begin{array}{l}\text { Visit specific sites only under the } \\
\text { supervision of trained or instructed } \\
\text { personnel }\end{array}$ & $\begin{array}{l}\text { Beeton (2006), Kern (2006), Armstrong } \\
\text { and Kern (2011) }\end{array}$ \\
\hline & $\begin{array}{l}\text { Providing services slowly that } \\
\text { increase the time and opportunity } \\
\text { cost for visitors (such as the queuing } \\
\text { system) }\end{array}$ & $\begin{array}{l}\text { Wearing and Neil (1999), Benfield (2000), } \\
\text { Beeton and Benfield (2002), Beeton } \\
\text { (2006), Kern (2006), Wearing, Archer } \\
\text { and Beeton (2007), Armstrong and Kern } \\
\text { (2011), Weiler } \text { et al. (2018) }\end{array}$ \\
\hline \multirow{3}{*}{$\begin{array}{l}\text { Physical } \\
\text { evidence }\end{array}$} & $\begin{array}{l}\text { Creating routes to guide tourists to } \\
\text { speed up their visits }\end{array}$ & UNWTO (2007), Weiler et al. (2018) \\
\hline & $\begin{array}{l}\text { Installing signs and boards to guide } \\
\text { tourists }\end{array}$ & UNWTO (2007) \\
\hline & $\begin{array}{l}\text { Use uniforms to distinguish workers } \\
\text { of each department to expedite the } \\
\text { visit }\end{array}$ & From opinions of tourism experts \\
\hline
\end{tabular}

\subsection{Konceptualni model}

Na Slici 1 prikazan je konceptualni model istraživanja koji obuhvaća dimenzije i elemente demarketinga turističkih destinacija na temelju literature.

\subsection{Conceptual model}

The research conceptual model included demarketing dimensions and elements of the tourism destinations based on the literature, presented in Figure 1. 


\section{Slika 1: Konceptualni model dimenzija i elemenata demarketinga turističkih destinacija}

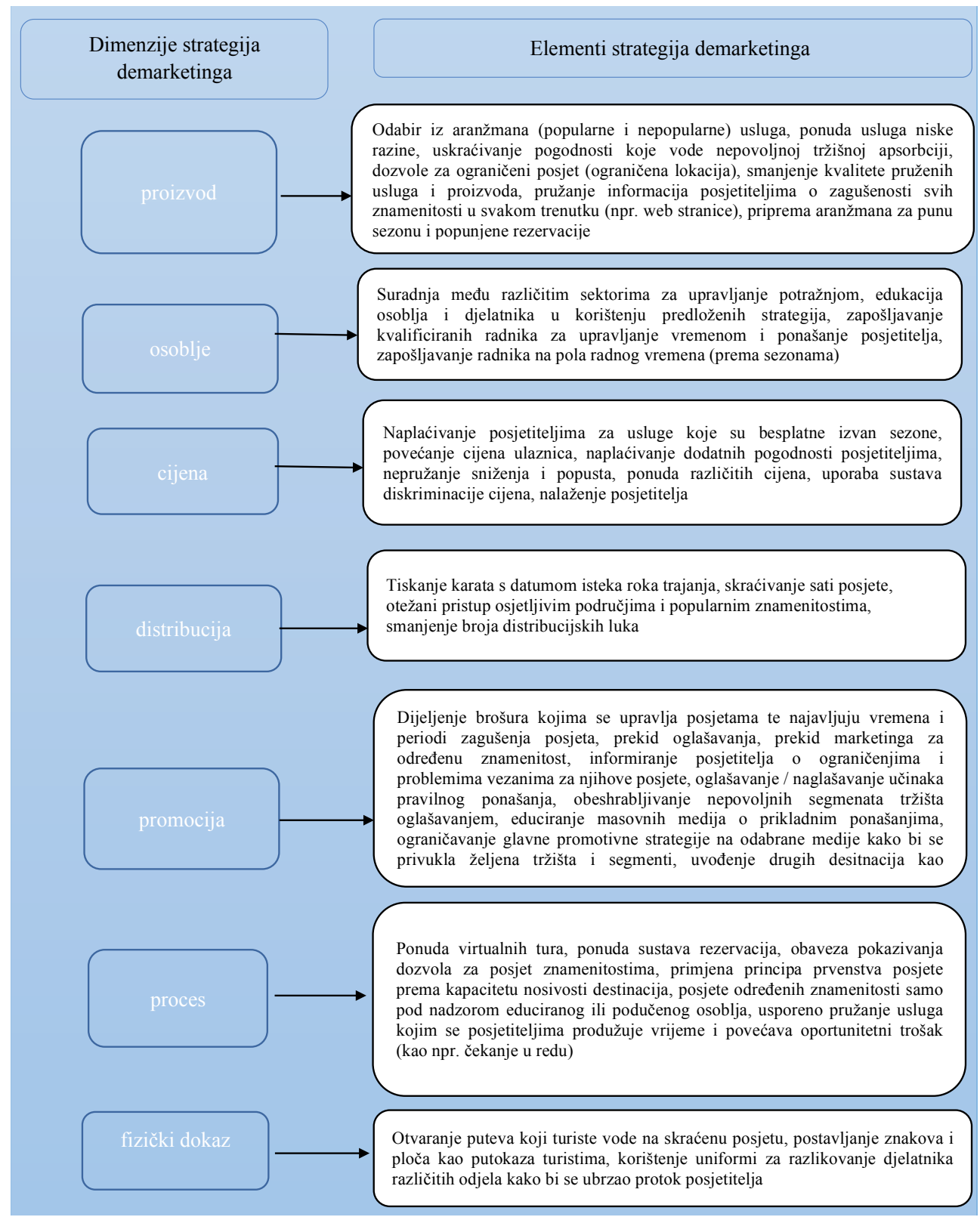




\section{Figure 1: The conceptual model of demarketing dimensions and elements of the tourism destinations}

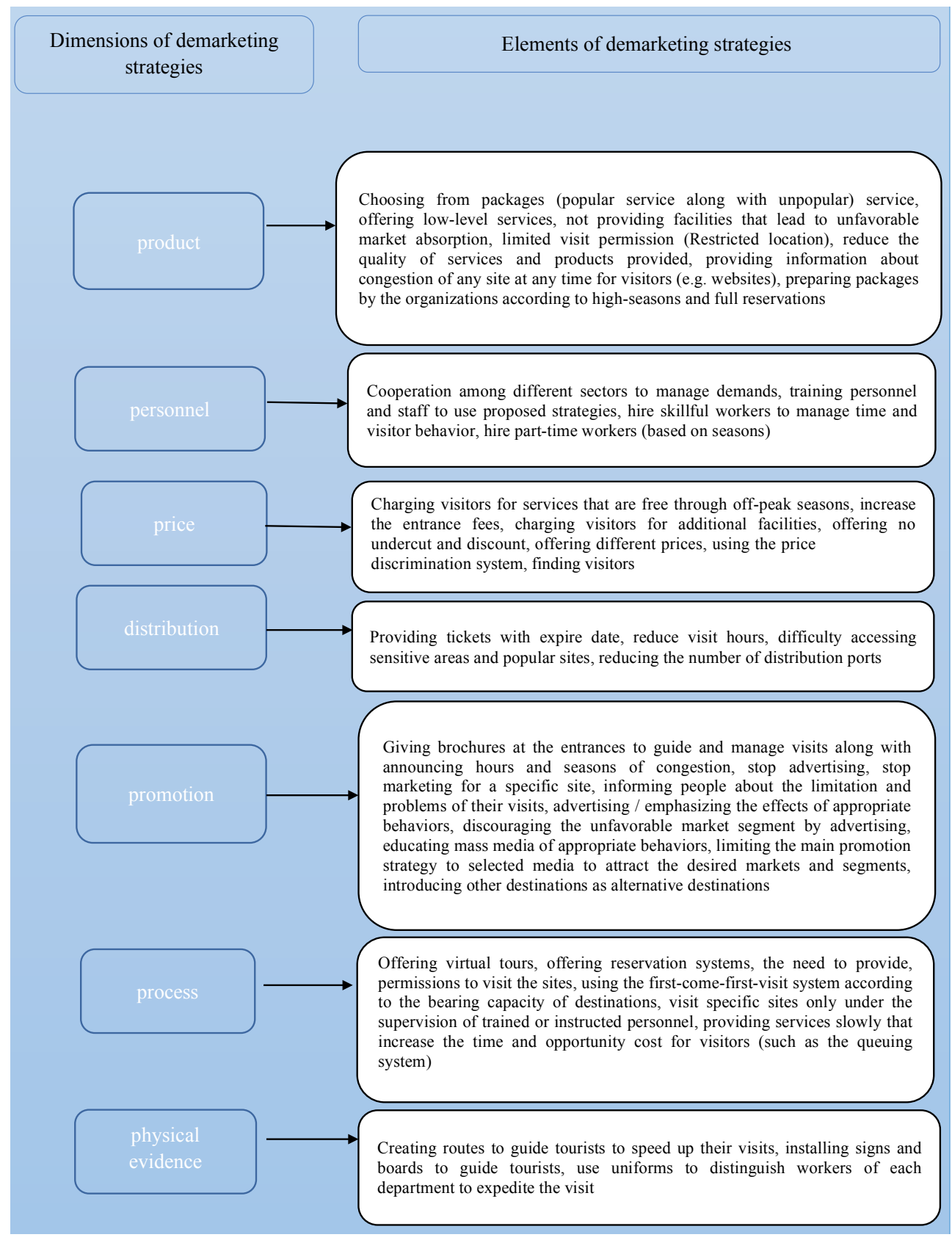




\section{METODOLOGIJA}

Ovaj je rad prikaz opisnog istraživanja $\mathrm{s}$ ciljem primjene rezultata u Kashanu. Nakon proučavanja literature o prethodnim istraživanjima, kako bi se dobile dimenzije i elementi strategija demarketinga, prikupljeni su podaci putem polustrukturiranih intervjua i tri vlastita upitnika.

U prvoj fazi razrađena su dva upitnika za dobivanje mišljenja stanovnika i turističkih vodiča o zagušenju u Kashanu u vrijeme vršne turističke sezone. Upitnici su razvijeni na temelju mišljenja eksperata od kojih su pet znanstvenici koji su posjetili grad u vrijeme glavne sezone, a ostalih pet su članovi turističke zajednice Kashana svjesni sezonskih problema grada. Nakon prve verzije, upitnik je revidiran i ponovno poslan stručnjacima na odobrenje nominalne validnosti konačne verzije. Tema trećeg upitnika bila je odabir prioriteta stategija demarketinga putem petostupne Likertove skale temeljene na prikupljenim podacima o elementima demarketinga iz literature i mišljenja znanstvenika $u$ području turizma (Tablica 1). Upitnik je poslan na validaciju i turističkim stručnjacima uzimajući u obzir njihova znanja o ovoj temi i problemima Kashana. Na kraju je njegova službena validnost i potvrđena.

Cronbachov koeficijent alfa bio je veći od 0,7 za sve varijable, a također se koristio i Kolmogorov-Smirnov test za provjeru normalne distribucije. Za određivanje percepcije stanovnika, turističkih vodiča, znanstvenika u području turizma i članova turističkih ureda Kashana o razini zagušenja korišten je $t$-test, a za utvrđivanje preopterećenih znamenitosti i vremena korištene su usporedbe sredina. Prioriteti varijabli i predloženih strategija demarketinga odabrani su na osnovi Friedmanovog testa.

U nastavku slijedi opis sudionika i uzorkovanja:

\section{METHODOLOGY}

This study was descriptive-survey research, and its findings that can be practiced in Kashan. First, using a library study, previous research was investigated to extract dimensions and elements of demarketing strategies. The data were collected using semi-structured interviews and a researcher-made questionnaire. Three different questionnaires were used in this study.

In the first phase, two different questionnaires were developed to investigate the point of view of the locals and tour guides active in tourism on the level of congestion in Kashan during the demand peak times. They were developed based on expert opinions, including five tourism academics who had visited the city during the peak seasons and five authorities in Kashan's tourism organization, aware of the city problems during the peak seasons. After the initial development, the questionnaire was revised and submitted again to the expert to approve the face validity of the final version. The third questionnaire was about prioritizing demarketing strategies. It was a five-point Likert scale questionnaire that developed based on the data collected about the elements of demarketing from the literature and tourism academics' opinion (Table 1). It was submitted to the expert to approve its face validity based on their awareness of the research topic and knowledge about the tourism problems of Kashan. Finally, its formal validity was confirmed.

Cronbach's alpha for all research variables was higher than 0.7. KolmogorovSmirnov test was also used to check the sample normality. The One Sample $t$-test was used to determine the perception of the congestion level by local people, tour guides, tourism academics, and authorities in Kashan; Average comparisons were also used to identify the sites and seasons facing demand congestion. The Friedman test was used to prioritize the variables and the proposed strategies for demarketing.

The research population and sampling are described below: 
- Turistički vodiči imaju svjedodžbu Turističke udruge Teherana kao turistički predstavnici; u vrijeme uzorkovanja 70 turističkih vodiča na turama po Kashanu sudjelovalo je u prigodnom uzorkovanju.

Od 208 službenih članova Udruge turističkih vodiča iz populacije uzorka isključeno je 68 vodiča eko tura, lokalnih i muzejskih vodiča i drugih službenika. Prema Cochranovoj formuli i Morganovoj tabeli razdijeljena su 103 upitnika u prikladnom uzorkovanju (među sudionicima skupova udruge i onima dostupnima putem interneta). Od te skupine, još 33 osobe su izuzete jer nisu bile aktivne u turama po Kashanu i tako je dobiven konačan uzorak populacije od 70 vodiča.

Razlog zašto turisti nisu uključeni u uzorkovanje je taj što su kao njihovi predstavnici bili odabrani vodiči, budući da oni mogu dati profesionalne stavove o svim problemima, posebno o prekomjernim zagušenjima o kojima slušaju primjedbe i mjšljenja turista. Kao direktni sudionici interakcije s turistima i stanovništvom, vodiči pokušavaju preuzeti odgovornost za zadovoljstvo turista. Štoviše, budući da se podaci nisu sakupljali na vrhuncu sezone, pribjeglo se rješenju da se uključe turistički vodiči koji vode po Kashanu.

- Stanovništvo uključuje 320.000 osoba koje borave i rade u Kashanu, a starije su od 18 godina. Temeljem Cochranove formule i Morganove tablice dovoljan bi bio uzorak od 384 osoba, a za istraživanje je sakupljeno 390 upitnika.

- Vlasti Kashana uključile su tri organizacije: Kulturno nasljeđe, Rukotvorine, i Turistička zajednica Kashana (kao planeri turizma), Gradsko poglavarstvo Kashana (kao izvršitelj odluka u turizmu), i Ured guvernera (kao nadzorna organizacija). Pet osoba iz svake organizacije sudjelovalo je u polu-strukturiranim osobnim intervjuima putem telefona (u trajanju od 90 do 105 minuta). U ovoj je fazi za uzorkovanje korištena metoda snježne grude.
- Tour guides were certified members of Tehran Tourism Association as representatives of tourists; 70 tour guides were providing Kashan tours during the study using convenience sampling.

The official number of the Tourist Guides Association was 208, from which 68 were eco-tour guides, local guides, museum guide, and other related people who were subtracted from the sample population. Using the Cochran formula and the Morgan table, 103 questionnaires were distributed through convenient sampling (among those attended the association's sessions and those accessible by the Internet). From this group, 33 people were not active in Kashan tours and were subtracted from the sample population. The final participants were 70 people.

The rationale for not including tourists in the sample population was that tour guides were selected as the representatives of the tourists since they can offer professional views on the problems faced by tourists, and even when tourists face congestion-related problems, they relay their opinions to tour guides. From direct interactions with tourists and local people, tour guides try to be accountable to tourist satisfaction. In addition, since the time of data collection was not a peak season, tour guides, active in Kashan tours, were resorted to collect the data.

- Local people were the residents and people working in Kashan, 18 years older and higher. 320.000 people live in this city. Based on the Cochran formula and Morgan's table, a sample including 384 people could suffice the research sample size; the researchers collected 390 questionnaires.

- Kashan authorities were from three Kashan's Cultural Heritage, Handicrafts, and Tourism Organization (as the planner of tourism industry), Kashan Municipality (as the operating agent of tourism decisions), and Office of the Governor (as the supervising organization). Five people from each organization participated in the semi-structured interviews in person 
- Turistički stručnjaci su znanstvenici u području turizma s kojima su provedeni osobni intervjui putem telefona $(\mathrm{u}$ trajanju od 25 do 60 minuta). Također je i u ovom uzorkovanju korištena metoda snježne grude.

\section{Struktura upitnika za vodiče $\mathbf{i}$ stanovništvo}

1. Odabir sezone i zagušenih znamenitosti Kashana: zagušeni mjeseci i mjesta imali su prvenstvo u upitniku.

2. Sudionici su zamoljeni da na Likertovoj ljestvici od „vrlo jako“ do „vrlo malo“ ocijene kako doživljavaju probleme zagušenosti.

\section{Stručnjaci: znanstvenici u području turizma i turističke vlasti}

1. Ocjena trenutnog stanja zagušenosti: u upitniku su stručnjaci zamoljeni ocijeniti trenutnu zagušenost Kashana na petočlanoj Likoetovoj ljestvici od „,vrlo jako“ do „vrlo malo“.

2. Strategija odabiranja prioriteta: postavljena su pitanja o rješenjima problema zagušenosti (unutar strategija demarketinga) te su predloženi pristupi čije su valjanosti stručnjaci ocijenili na petočlanoj Likertovoj ljestvici od „vrlo jako“ do „vrlo malo“.

\section{STUDIJA SLUČAJA: KASHAN}

Kashan se prostire na području od oko $10.000 \mathrm{~m}^{2} \mathrm{u}$ blizini središnje pustinje Irana između planina i pustinje te graniči sa slanim jezerima u provincijama Semnan i Qom na sjeveru, Natanz i Meymeh na jugu, Ardestan na istoku i Delijan na zapadu. Kashan je oduvijek bio značajan grad zbog svog položaja na trgovačkom putu i prometnici između Teherana i mjesta na jugu Irana. Najpoznatije selo kraj Kashana je Abyaneh. Kashan je od or via telephone (the time of the interviews were between 90 minutes up to 105 minutes). Snowball sampling was used in this step.

- Tourism experts were 30 tourism academics and interviewed in person and via telephone (the time of the interviews were between 25 minutes up to one hour). Snowball sampling was used in this step.

\section{The questionnaire structure for the tour guides and local people}

1. Season selection and the congested sites of Kashan: the congested months and sites were prioritized in this questionnaire.

2 . The participants were asked to choose the perceived congestion problems based on a five-point Likert scale, from 'very much' to 'very little'.

\section{Experts: academics and tourism authorities}

1. Present congestion: in the questionnaire, the experts were asked to rate the present congestion Kashan on a five-point Likert scale, from 'very much' to 'very little'.

2. Strategy prioritization: regarding solutions for the congestion problems (within demarketing strategies), the experts were asked to rate the significance of the approaches on a five-point Likert scale, from 'very much' to 'very little'.

\section{CASE STUDY: KASHAN}

Kashan covers an area of approximately $10.000 \mathrm{~m}^{2}$ and is located in the proximity to the Central Desert of Iran. It is limited by the Salt Lake of Semnan and Qom provinces from the north, by Natanz and Meymeh from the south, by Ardestan from the east, and by Delijan from the west. The city is between nearby mountains and the desert. Due to its presence on trade and inter-city connection roads, Kashan has always been a significant city; the city is next to an important highway 
Teherana udaljen $230 \mathrm{~km}$, od Qoma 95, a od Isfahana $210 \mathrm{~km}$. Zbog lokacije na stjecištu puteva između istočnih, zapadnih, sjevernih i južnih provincija, grad ugošćuje mnoge posjetitelje svake godine (Kulturna baština, rukotvorine i turistička zajednica Kashana; Općina Kashan, 2020). U okolici se nalaze turstička mjesta Mashhad Ardehal, Niasar i Qamsar pa Kashan, kao dio cijele provincije, može konkurirati turizmu Isfahana.

Od 14 međunarodnih turističkih atrakcija Kashana, koje većinom potječu iz doba Qajar, 13 su kulturno-povijesne, a jedna je prirodna atrakcija (Golabgiri ili radionice ,izrade ružine vodice“ u Gamsaru). Kashan ima 54 nacionalne turističke atrakcije, uglavnom iz doba Qajar, Seljuq i Safavid te 96 županijske atrakcije vezane za povijest i kulturu iz doba Qajar i Safavid.

Najvažnija ciljana domaća tržišta Kashana su Teheran, Kerman, Yazd i Isfahan, a međunarodna su Francuska, Kina, Italija, Njemačka, Japan, Nizozemska, Australija i Španjolska. Iako je broj međunarodnih turista veći od domaćeg, čini se da je kvaliteta obima nacionalnih tržišta općenito veća. Teheran zauzima otprilike $75 \%$ nacionalnog tržišta pa su ostala tržišta puno manje zastupljena.

\section{REZULTATI}

\section{Percipirana zagušenost}

Temeljem odgovora turističkih vodiča i stanovništva u proljeće su se pojavila tri prioriteta zagušenja potražnje. that connects the capital city, Tehran, to the southern cities of Iran. The most well-known village in Kashan is Abyaneh. The distances from Kashan to Tehran, Qom, and Isfahan are 230, 95, and $210 \mathrm{~km}$ respectively. Located on a great chain of highways and connected to eastern, western, northern, and southern provinces, the city is a host for many passing visitors annually (Kashan's Cultural Heritage, Handicrafts and Tourism Organization; Kashan Municipality, 2020). Kashan's tourism hubs include areas around Mashhad Ardehal, Niasar, and Qamsar, and as part of Isfahan it can compete with the tourism sector of Isfahan.

There are 14 international tourist attractions in Kashan and most of them are related to the Qajar era. Among them, 13 attractions are historical-cultural and one of them is natural (Golabgiri or 'making rosewater' workshops in Gamsar). There are also 54 national tourist attractions in Kashan, most of which related to the Qajar, the Seljuq, and the Safavid eras. There are 96 provincial attractions in the city, mostly historical-cultural and related to the Qajar and the Safavid eras.

The most important national target markets of Kashan are for Tehran, Kerman, Yazd, and Isfahan, whereas the most important international target markets are for France, China, Italy, Germany, Japan, the Netherlands, Australia, and Spain. Although the number of tourists in the international markets is higher than the ones of Iran, it seems that the volume quality of the national markets is generally higher. Among the national markets, approximately $75 \%$ of the whole market is supplied by the Tehran market, and other national markets are allocated a much smaller volume.

\section{FINDINGS}

\section{Perceived congestion}

Based on the findings from the tour guides and local people, there were three demand congestion priorities during spring. 


\section{Tablica 2: Percipirana razina zagušenja znamenitosti prema odgovorima turističkih vodiča}

\begin{tabular}{|l|c|c|}
\hline Turistička znamenitost & $\begin{array}{c}\text { Srednja } \\
\text { ocjena }\end{array}$ & Prioritet \\
\hline $\begin{array}{l}\text { Tradicionalna tržnica } \\
\text { Kashana }\end{array}$ & 10,17 & 1 \\
\hline Vrt Finn & 9,03 & 2 \\
\hline $\begin{array}{l}\text { Destilerije ružine } \\
\text { vodice (Niasar } \\
\text { Ghamsar) }\end{array}$ & 8,30 & 3 \\
\hline Povijesne kuće & 8,18 & 4 \\
\hline Abyane & 4,95 & 5 \\
\hline $\begin{array}{l}\text { Regija Niasar (sa } \\
\text { slapom, špiljom i } \\
\text { hramom vatre) }\end{array}$ & 7,92 & 6 \\
\hline $\begin{array}{l}\text { Pustinja i odmorište za } \\
\text { karavane Maranjab }\end{array}$ & 7,53 & 7 \\
\hline $\begin{array}{l}\text { Podzemni grad } \\
\text { Noshabad }\end{array}$ & 7,45 & 8 \\
\hline $\begin{array}{l}\text { Grobnica Sohrab } \\
\text { Sepehri }\end{array}$ & 7,30 & 9 \\
\hline
\end{tabular}

Usporedna analiza pokazala je da je Kashanska tradicionalna tržnica dobila najveću ocjenu $(10,17)$, dok je na zadnjem mjestu ostao Distrikt Barzak $(4,86)$.
Table 2: The perceived level of site congestion reported by tour guides

\begin{tabular}{|l|r|c|}
\hline \multicolumn{1}{|c|}{ Tourism site } & $\begin{array}{c}\text { Average } \\
\text { rating }\end{array}$ & Priority \\
\hline $\begin{array}{l}\text { Kashan traditional } \\
\text { market }\end{array}$ & 10.17 & 1 \\
\hline Finn Garden & 9.03 & 2 \\
\hline $\begin{array}{l}\text { Rose water distillation } \\
\text { sites (Niasar and } \\
\text { Ghamsar) }\end{array}$ & 8.30 & 3 \\
\hline Historic houses & 8.18 & 4 \\
\hline Abyane & 4.95 & 5 \\
\hline $\begin{array}{l}\text { Niasar region (including } \\
\text { waterfall, cave and fire } \\
\text { temple) }\end{array}$ & 7.92 & 6 \\
\hline $\begin{array}{l}\text { Maranjab desert and } \\
\text { caravanserai }\end{array}$ & 7.53 & 7 \\
\hline $\begin{array}{l}\text { Noshabad underground } \\
\text { city }\end{array}$ & 7.45 & 8 \\
\hline $\begin{array}{l}\text { Tomb of Sohrab } \\
\text { Sepehri }\end{array}$ & 7.30 & 9 \\
\hline
\end{tabular}

The average comparisons showed that Kashan's Traditional Bazar owns the highest visit average of 10.17, and Barzak District occupies the lowest stand by an average of 4.86 .

Tablica 3: Percipirana zagušenost prema statističkom uzorku

\begin{tabular}{|l|c|c|c|c|}
\hline $\begin{array}{c}\text { Percipirano } \\
\text { zagušenje }\end{array}$ & Populacija & $\begin{array}{c}\text { Srednja } \\
\text { vrijednost }\end{array}$ & $\begin{array}{c}\text { Standardna } \\
\text { devijacija }\end{array}$ & $\begin{array}{c}\text { Standardna } \\
\text { greška sredine }\end{array}$ \\
\hline Vodiči & 70 & 3,3013 &, 54169 &, 06618 \\
\hline Stanovnici & 390 & 2,8562 &, 65379 &, 03269 \\
\hline Znanstvenici & 27 & 4,4074 &, 50071 &, 09636 \\
\hline Lokalni stručnjaci & 30 & 4,4074 &, 50071 &, 09636 \\
\hline
\end{tabular}

Table 3: The perceived congestion by the statistical sample

\begin{tabular}{|l|c|c|c|c|}
\hline Perceived congestion & Population & Mean & $\begin{array}{c}\text { Standard } \\
\text { deviation }\end{array}$ & $\begin{array}{c}\text { Mean standard } \\
\text { error }\end{array}$ \\
\hline Guides & 70 & 3.3013 & .54169 & .06618 \\
\hline Local citizens & 390 & 2.8562 & .65379 & .03269 \\
\hline Academic experts & 27 & 4.4074 & .50071 & .09636 \\
\hline Local experts & 30 & 4.4074 & .50071 & .09636 \\
\hline
\end{tabular}




\section{Percepcija razine zagušenja}

Tablica 4: Percipirana razina zagušenja prema statističkom uzorku

\begin{tabular}{|c|c|c|c|c|c|c|}
\hline \multirow{3}{*}{$\begin{array}{l}\text { Perceipirano } \\
\text { zagušenje }\end{array}$} & \multicolumn{6}{|c|}{ Vrijednost testa $=3$} \\
\hline & \multirow[t]{2}{*}{$\mathrm{t}$} & \multirow{2}{*}{$\begin{array}{l}\text { Stupanj } \\
\text { slobode }\end{array}$} & \multirow{2}{*}{$\begin{array}{c}\text { Značajne } \\
\text { brojke } \\
\text { (sig) }\end{array}$} & \multirow{2}{*}{$\begin{array}{c}\text { Razlika } \\
\text { srednjih } \\
\text { vrijednosti }\end{array}$} & \multicolumn{2}{|c|}{$\begin{array}{l}\text { Intervali pouzdanosti } \\
95 \%\end{array}$} \\
\hline & & & & & Donji & Gornji \\
\hline Vodiči & 4,553 & 66 & 000 & ,30132 & , 1692 & ,4335 \\
\hline $\begin{array}{l}\text { Lokalno } \\
\text { stanovništvo }\end{array}$ & $-4,398$ & 399 &, 000 &,- 14377 &,- 2080 &,- 0795 \\
\hline Znanstvenici & 14,605 & 26 &, 000 & 1,40741 & 1,2093 & 1,6055 \\
\hline Lokalni stručnjaci & 17,725 & 12 & 000 & 1,846 & 1,62 & 2,07 \\
\hline
\end{tabular}

\section{The perception of the congestion level}

Table 4: The perceived level of congestion by the statistical sample

\begin{tabular}{|c|c|c|c|c|c|c|}
\hline \multirow{3}{*}{$\begin{array}{l}\text { Perceived } \\
\text { congestion }\end{array}$} & \multicolumn{6}{|c|}{ Test value $=3$} \\
\hline & \multirow[t]{2}{*}{$\mathrm{t}$} & \multirow{2}{*}{$\begin{array}{l}\text { Degree of } \\
\text { freedom }\end{array}$} & \multirow{2}{*}{$\begin{array}{l}\text { Significant } \\
\text { figures } \\
(\text { sig) }\end{array}$} & \multirow{2}{*}{$\begin{array}{l}\text { Difference } \\
\text { in mean }\end{array}$} & \multicolumn{2}{|c|}{$\begin{array}{c}\text { Confidence intervals } \\
95 \%\end{array}$} \\
\hline & & & & & Lower & Upper \\
\hline Guides & 4.553 & 66 & .000 & .30132 & .1692 & .4335 \\
\hline Local citizens & -4.398 & 399 & .000 & -.14377 & -.2080 & -.0795 \\
\hline Academic experts & 14.605 & 26 & .000 & 1.40741 & 1.2093 & 1.6055 \\
\hline Local experts & 17.725 & 12 & .000 & 1.846 & 1.62 & 2.07 \\
\hline
\end{tabular}

Analiza podataka dobivenih iz upitnika turističkih vodiča pokazala je njihove visoke procjene zagušenja turistima u gradu. Živeći u izravnom dodiru i međusobnoj interakciji s turistima i stanovništvom u nastojanju da zadovolje portrebe posjetitelja, oni su potvrdili da se turisti žale na zagušenost $u$ određenim vremenima i veliku prezagušenost $u$ vrijeme visoke sezone uz zagušenost potražnje. Lokalne vlasti i stručnjaci izrazili su uvjerenje da je percipirana razina zagušenja visoka i da su poduzeli inicijative za smanjenje zagušenja turizmom u Povjerenstvu kriznog menadžmenta Nowruza. Oni znanstvenici koji ne uživaju koristi od turizma u Kashanu ocijenili su da je zagušenost turizmom na pretjerano visokoj razini dok je lokalno stanovništvo dalo nižu procjenu razine zagušenosti.
The data analysis of the tour guide questionnaires shows that they estimated a high level of tourist congestion in the city. Being in direct contact and interaction with the tourists and local people, they attempt to satisfy the need of the tourists during the visit. They acknowledged that the tourist complaints and dissatisfaction were during the congestion periods, and they observed and perceived high or overfull congestion during high seasons with demand congestion. Local authorities and experts believed that the perceived level of congestion was high and they had taken initiatives to reduce tourist congestion in the Committee of Nowruz Crisis Management. The tourism academics, those who are not beneficiaries of the tourism industry of Kashan, estimated the high and excessive level of tourism congestion. The local people generally rated tourist congestion lower. 


\section{Poredak strategija demarketinga}

Tablica 5: Poredak dimenzija demaketinga u Kashanu prema znanstvenicima i lokalnim vlastima

\begin{tabular}{|l|c|c|c|c|}
\hline $\begin{array}{c}\text { Elementi } \\
\text { demarketinga }\end{array}$ & $\begin{array}{c}\text { Srednja vrijednost } \\
\text { za lokalne } \\
\text { stručnjake }\end{array}$ & $\begin{array}{c}\text { Ocjena lokalnih } \\
\text { stručnjaka }\end{array}$ & $\begin{array}{c}\text { Srednja vrijednost } \\
\text { za znanstvenike }\end{array}$ & $\begin{array}{c}\text { Ocjena } \\
\text { znanstvenika }\end{array}$ \\
\hline Osoblje & 5,88 & 1 & 5,10 & 1 \\
\hline Cijena & 4,65 & 2 & 4,47 & 2 \\
\hline Distribucija & 2,38 & 7 & 4,10 & 3 \\
\hline Promocija & 4,19 & 3 & 4,00 & 4 \\
\hline Proces & 4,04 & 4 & 3,93 & 6 \\
\hline Proizvod & 3,15 & 6 & 3,33 & 7 \\
\hline Fizčki dokaz & 3,69 & 5 & 3,07 & \\
\hline
\end{tabular}

\section{Prioritizing demarketing strategies}

Table 5. Prioritizing the dimensions of demarketing strategies in Kashan by the academics and local authorities

\begin{tabular}{|l|c|c|c|c|}
\hline $\begin{array}{c}\text { Demarketing } \\
\text { elements }\end{array}$ & $\begin{array}{c}\text { Average for local } \\
\text { experts }\end{array}$ & $\begin{array}{c}\text { Rank of local } \\
\text { experts }\end{array}$ & $\begin{array}{c}\text { Average for } \\
\text { university experts }\end{array}$ & $\begin{array}{c}\text { Rank of academic } \\
\text { experts }\end{array}$ \\
\hline Staff & 5.88 & 1 & 5.10 & 1 \\
\hline Price & 4.65 & 2 & 4.47 & 2 \\
\hline Distribution & 2.38 & 7 & 4.10 & 3 \\
\hline Promotion & 4.19 & 3 & 4.00 & 4 \\
\hline Process & 4.04 & 4 & 3.93 & 5 \\
\hline The product & 3.15 & 6 & 3.33 & 6 \\
\hline Physical evidence & 3.69 & 5 & 3.07 & 7 \\
\hline
\end{tabular}

Tablica 6 prikazuje srednju vrijednost i rangiranje percipiranih elemenata demarketinga prema ocjeni lokalnih stručnjaka i znanstvenika.
The average and arrangement rank of the perceived demarketing elements by the local authorities and academics are shown in Table 6 . 
Golnoush Zeidabadi, Seyed Mojtaba Mahmoudzadeh, Marziye Hemati: Strategija demarketinga...

\section{Tablica 6: Ocjena elemenata strategije demarketinga u Kashanu prema lokalnim stručnjacima i znanstvenicima}

\begin{tabular}{|c|c|c|c|c|c|}
\hline $\begin{array}{c}\text { Dimenzije } \\
\text { strategija } \\
\text { demarketinga }\end{array}$ & Elementi strategije demarketinga & $\begin{array}{c}\text { Srednja } \\
\text { vrijednost } \\
\text { lokalnih } \\
\text { stručnjaka }\end{array}$ & $\begin{array}{l}\text { Rangiranje } \\
\text { lokalnih } \\
\text { stručnjaka }\end{array}$ & $\begin{array}{c}\text { Srednja } \\
\text { vrijednost } \\
\text { znanstvenika }\end{array}$ & $\begin{array}{l}\text { Rangiranje } \\
\text { znanstvenika }\end{array}$ \\
\hline \multirow{7}{*}{ Proizvod } & $\begin{array}{l}\text { Aranžmani pripremljeni za visoku sezonu i pune } \\
\text { rezervacije }\end{array}$ & 5,08 & 1 & 4,73 & 2 \\
\hline & Smanjenje kvalitete usluge i proizvoda & 4,46 & 2 & 3,53 & 5 \\
\hline & Ograničene dozvole za posjet (određena mjesta) & 3,92 & 3 & 4,07 & 3 \\
\hline & $\begin{array}{l}\text { Odabir iz paketa aranžmana (populare usluge s } \\
\text { nepopularnima) }\end{array}$ & 4,38 & 4 & 3,10 & 7 \\
\hline & $\begin{array}{l}\text { Informacije za posjetitelje o zagušenjima bilo koje } \\
\text { znamenitosti u bilo koje vrijeme }\end{array}$ & 4,36 & 5 & 5,33 & 1 \\
\hline & $\begin{array}{l}\text { Pogodnosti koje vode ka nepovoljnoj tržišnoj } \\
\text { apsorpciji }\end{array}$ & 3,12 & 6 & 3,90 & 4 \\
\hline & Ponuda usluga niske razine & 2,58 & 7 & 3,33 & 6 \\
\hline \multirow{4}{*}{ Osoblje } & $\begin{array}{l}\text { Suradnja među različitim sektorima za upravljanje } \\
\text { potražnjom }\end{array}$ & 2,92 & 1 & 2,73 & 2 \\
\hline & $\begin{array}{l}\text { Zapošljavanje radnika na pola radnog vremena } \\
\text { (prema sezonama) }\end{array}$ & 2,65 & 2 & 1,83 & 4 \\
\hline & $\begin{array}{l}\text { Edukacija osoblja i djelatnika u korištenju } \\
\text { predloženih strategija }\end{array}$ & 2,46 & 3 & 2,90 & 1 \\
\hline & $\begin{array}{l}\text { Zapošljavanje kvalificiranih radnika za upravljanje } \\
\text { vremenom i ponašanje posjetitelja }\end{array}$ & 1,96 & 4 & 2,53 & 3 \\
\hline \multirow{7}{*}{ Cijena } & Povećanje cijena ulaznica & 4,50 & 1 & 4,60 & 1 \\
\hline & $\begin{array}{l}\text { Naplaćivanje posjetiteljima za usluge koje su } \\
\text { besplatne izvan sezone }\end{array}$ & 4,31 & 2 & 4,57 & 2 \\
\hline & Naplaćivanje dodatnih pogodnosti posjetiteljima & 4,15 & 3 & 3,80 & 5 \\
\hline & Uporaba sustava diskriminacije cijena & 4,04 & 4 & 4,17 & 3 \\
\hline & Ponuda različitih cijena & 4,00 & 5 & 4,03 & 4 \\
\hline & Ne nuđenje sniženja i popusta & 3,58 & 6 & 3,60 & 6 \\
\hline & Nalaženje posjetitelja & 3,42 & 7 & 3,23 & 7 \\
\hline \multirow{4}{*}{ Distribucija } & $\begin{array}{l}\text { Otežani pristup osjetljivim područjima i popularnim } \\
\text { znamenitostima }\end{array}$ & 3,04 & 1 & 2,77 & 1 \\
\hline & \begin{tabular}{|l|} 
Tiskanje karata s datumom isteka roka trajanja \\
\end{tabular} & 3,00 & 2 & 2,73 & 2 \\
\hline & Skraćivanje sati posjete & 2,50 & 3 & 2,17 & 4 \\
\hline & \begin{tabular}{|l|} 
Smanjenje broja distribucijskih luka \\
\end{tabular} & 1,46 & 4 & 2,33 & 3 \\
\hline \multirow{7}{*}{ Promocija } & Obustava marketinga za određenu znamenitost & 6,62 & 1 & 5,96 & 8 \\
\hline & $\begin{array}{l}\text { Dijeljenje brošura kojima se upravlja posjetama te } \\
\text { najavljuju vremena i periodi zagušenja posjeta }\end{array}$ & 6,23 & 2 & 5,04 & 3 \\
\hline & $\begin{array}{l}\text { Informiranje posjetitelja o ograničenjima i } \\
\text { problemima vezanima za posjete }\end{array}$ & 5,62 & 3 & 5,46 & 1 \\
\hline & Educiranje masovnih medija o prikladnim ponašanjima & 5,50 & 4 & 4,86 & 4 \\
\hline & Obustava oglašavanja & 4,65 & 5 & 4,46 & 7 \\
\hline & $\begin{array}{l}\text { Uvođenje drugih destinacija kao alternativnih } \\
\text { destinacija }\end{array}$ & 5,31 & 6 & 5,21 & 2 \\
\hline & $\begin{array}{l}\text { Obeshrabljivanje nepovoljnih segmenata tržišta } \\
\text { oglašavanjem }\end{array}$ & 4,46 & 7 & 4,61 & 9 \\
\hline
\end{tabular}




\begin{tabular}{|c|c|c|c|c|c|}
\hline $\begin{array}{c}\text { Dimenzije } \\
\text { strategija } \\
\text { demarketinga }\end{array}$ & Elementi strategije demarketinga & $\begin{array}{c}\text { Srednja } \\
\text { vrijednost } \\
\text { lokalnih } \\
\text { stručnjaka }\end{array}$ & $\begin{array}{l}\text { Rangiranje } \\
\text { lokalnih } \\
\text { stručnjaka }\end{array}$ & $\begin{array}{c}\text { Srednja } \\
\text { vrijednost } \\
\text { znanstvenika }\end{array}$ & $\begin{array}{l}\text { Rangiranje } \\
\text { znanstvenika }\end{array}$ \\
\hline \multirow{2}{*}{ Promocija } & $\begin{array}{l}\text { Oglašavanje / naglašavanje učinaka pravilnog } \\
\text { ponašanja }\end{array}$ & 3,73 & 8 & 4,64 & 6 \\
\hline & $\begin{array}{l}\text { Ograničavanje glavne promotivne strategije na odabrane } \\
\text { medije kako bi se privukla željena tržišta i segmenti }\end{array}$ & 2,88 & 9 & 4,75 & 5 \\
\hline \multirow{6}{*}{ Process } & Ponuda sustava rezervacija & 4,23 & 1 & 4,30 & 1 \\
\hline & $\begin{array}{l}\text { Posjete određenih znamenitosti samo pod nadzorom } \\
\text { educiranog ili podučenog osoblja }\end{array}$ & 3,88 & 2 & 3,47 & 4 \\
\hline & $\begin{array}{l}\text { Primjena principa prvenstva posjete prema } \\
\text { kapacitetu nosivosti destinacija }\end{array}$ & 3,73 & 3 & 3,93 & 2 \\
\hline & $\begin{array}{l}\text { Obaveza pokazivanja dozvola za posjet } \\
\text { znamenitostima }\end{array}$ & 3,31 & 4 & 3,53 & 3 \\
\hline & Ponuda virtualnih tura & 3,19 & 5 & 2,60 & 6 \\
\hline & $\begin{array}{l}\text { Usporeno pružanje usluga kojim se posjetiteljima } \\
\text { produžuje vrijeme i povećava oportunitetni trošak } \\
\text { (kao npr. čekanje u redu) }\end{array}$ & 2,65 & 6 & 3,17 & 5 \\
\hline \multirow{3}{*}{ Fizički dokaz } & $\begin{array}{l}\text { Korištenje uniformi za razlikovanje djelatnika } \\
\text { različitih odjela kako bi se ubrzao protok posjetitelja }\end{array}$ & 2,27 & 1 & 1,47 & 3 \\
\hline & Postavljanje znakova i ploča kao putokaza turistima & 1,98 & 2 & 2,40 & 1 \\
\hline & $\begin{array}{l}\text { Otvaranje puteva koji turiste vode na skraćenu } \\
\text { posjetu }\end{array}$ & 1,80 & 3 & 2,13 & 2 \\
\hline
\end{tabular}

\section{Table 6: Prioritizing the elements of demarketing strategies in Kashan by the academics and local authorities}

\begin{tabular}{|c|c|c|c|c|c|}
\hline $\begin{array}{c}\text { Dimensions } \\
\text { of } \\
\text { demarketing } \\
\text { strategies }\end{array}$ & Elements of demarketing strategies & $\begin{array}{l}\text { Average } \\
\text { for local } \\
\text { experts }\end{array}$ & $\begin{array}{c}\text { Rank order } \\
\text { for local } \\
\text { experts }\end{array}$ & $\begin{array}{c}\text { Average of } \\
\text { academic } \\
\text { experts }\end{array}$ & $\begin{array}{l}\text { Rank order } \\
\text { for academic } \\
\quad \text { experts }\end{array}$ \\
\hline \multirow{7}{*}{ Product } & $\begin{array}{l}\text { Preparing packages by the organizations according } \\
\text { to high-seasons and full reservations }\end{array}$ & 5.08 & 1 & 4.73 & 2 \\
\hline & $\begin{array}{l}\text { Reduce the quality of services and products } \\
\text { provided }\end{array}$ & 4.46 & 2 & 3.53 & 5 \\
\hline & Limited visit permission (Restricted location) & 3.92 & 3 & 4.07 & 3 \\
\hline & $\begin{array}{l}\text { Choosing from packages (popular service along } \\
\text { with unpopular) }\end{array}$ & 4.38 & 4 & 3.10 & 7 \\
\hline & $\begin{array}{l}\text { Providing information about congestion of any site } \\
\text { at any time for visitors }\end{array}$ & 4.36 & 5 & 5.33 & 1 \\
\hline & $\begin{array}{l}\text { Not providing facilities that lead to unfavorable } \\
\text { market absorption }\end{array}$ & 3.12 & 6 & 3.90 & 4 \\
\hline & Offering low-level services & 2.58 & 7 & 3.33 & 6 \\
\hline \multirow{4}{*}{ Personnel } & $\begin{array}{l}\text { Cooperation among different sectors to manage } \\
\text { demands }\end{array}$ & 2.92 & 1 & 2.73 & 2 \\
\hline & Hire part-time workers (based on seasons) & 2.65 & 2 & 1.83 & 4 \\
\hline & $\begin{array}{l}\text { Training personnel and staff to use proposed } \\
\text { strategies }\end{array}$ & 2.46 & 3 & 2.90 & 1 \\
\hline & $\begin{array}{l}\text { Hire skillful workers to manage time and visitor } \\
\text { behavior }\end{array}$ & 1.96 & 4 & 2.53 & 3 \\
\hline
\end{tabular}


Golnoush Zeidabadi, Seyed Mojtaba Mahmoudzadeh, Marziye Hemati: Strategija demarketinga...

\begin{tabular}{|c|c|c|c|c|c|}
\hline $\begin{array}{l}\text { Dimensions } \\
\text { of } \\
\text { demarketing } \\
\text { strategies }\end{array}$ & Elements of demarketing strategies & $\begin{array}{l}\text { Average } \\
\text { for local } \\
\text { experts }\end{array}$ & $\begin{array}{c}\text { Rank order } \\
\text { for local } \\
\text { experts }\end{array}$ & $\begin{array}{l}\text { Average of } \\
\text { academic } \\
\text { experts }\end{array}$ & $\begin{array}{l}\text { Rank order } \\
\text { for academic } \\
\quad \text { experts }\end{array}$ \\
\hline \multirow{7}{*}{ Price } & Increase the entrance fees & 4.50 & 1 & 4.60 & 1 \\
\hline & $\begin{array}{l}\text { Charging visitors for services that are free through } \\
\text { off-peak seasons }\end{array}$ & 4.31 & 2 & 4.57 & 2 \\
\hline & Charging visitors for additional facilities & 4.15 & 3 & 3.80 & 5 \\
\hline & Using the price discrimination system & 4.04 & 4 & 4.17 & 3 \\
\hline & Offering different prices & 4.00 & 5 & 4.03 & 4 \\
\hline & Offering no undercut and discount & 3.58 & 6 & 3.60 & 6 \\
\hline & Finding visitors & 3.42 & 7 & 3.23 & 7 \\
\hline \multirow{4}{*}{ Distribution } & $\begin{array}{l}\text { Difficulty accessing sensitive areas and popular } \\
\text { sites }\end{array}$ & 3.04 & 1 & 2.77 & 1 \\
\hline & Providing tickets with expire date & 3.00 & 2 & 2.73 & 2 \\
\hline & Reduce visit hours & 2.50 & 3 & 2.17 & 4 \\
\hline & Reducing the number of distribution ports & 1.46 & 4 & 2.33 & 3 \\
\hline \multirow{9}{*}{ Promotion } & Stop marketing for a specific site & 6.62 & 1 & 5.96 & 8 \\
\hline & $\begin{array}{l}\text { Giving brochures at the entrances to guide and } \\
\text { manage visits along with announcing hours and } \\
\text { seasons of congestion }\end{array}$ & 6.23 & 2 & 5.04 & 3 \\
\hline & $\begin{array}{l}\text { Informing people about the limitations and } \\
\text { problems of their visits }\end{array}$ & 5.62 & 3 & 5.46 & 1 \\
\hline & Educating mass media of appropriate behaviors & 5.50 & 4 & 4.86 & 4 \\
\hline & Stop advertising & 4.65 & 5 & 4.46 & 7 \\
\hline & $\begin{array}{l}\text { Introduce other destinations as alternative } \\
\text { destinations }\end{array}$ & 5.31 & 6 & 5.21 & 2 \\
\hline & $\begin{array}{l}\text { Discouraging the unfavorable market segment by } \\
\text { advertising }\end{array}$ & 4.46 & 7 & 4.61 & 9 \\
\hline & $\begin{array}{l}\text { Advertising / emphasizing the effects of } \\
\text { appropriate behaviors }\end{array}$ & 3.73 & 8 & 4.64 & 6 \\
\hline & $\begin{array}{l}\text { Limiting the main promotion strategy to selected } \\
\text { media to attract the desired markets and segments }\end{array}$ & 2.88 & 9 & 4.75 & 5 \\
\hline \multirow{6}{*}{ Process } & Offering reservation systems & 4.23 & 1 & 4.30 & 1 \\
\hline & $\begin{array}{l}\text { Visit specific sites only under the supervision of } \\
\text { trained or instructed personnel }\end{array}$ & 3.88 & 2 & 3.47 & 4 \\
\hline & $\begin{array}{l}\text { Using the first-come-first-visit system according to } \\
\text { the bearing capacity of destinations }\end{array}$ & 3.73 & 3 & 3.93 & 2 \\
\hline & The need to provide Permissions to visit the sites & 3.31 & 4 & 3.53 & 3 \\
\hline & Offering a virtual tour & 3.19 & 5 & 2.60 & 6 \\
\hline & $\begin{array}{l}\text { Providing services slowly that increase the time } \\
\text { and opportunity cost for visitors (such as the } \\
\text { queuing system) }\end{array}$ & 2.65 & 6 & 3.17 & 5 \\
\hline \multirow{3}{*}{$\begin{array}{l}\text { Physical } \\
\text { evidence }\end{array}$} & $\begin{array}{l}\text { Use uniforms to distinguish workers of each } \\
\text { department to expedite the visit }\end{array}$ & 2.27 & 1 & 1.47 & 3 \\
\hline & Installing signs and boards to guide tourists & 1.98 & 2 & 2.40 & 1 \\
\hline & $\begin{array}{l}\text { Creating routes to guide tourists to speed up their } \\
\text { visits }\end{array}$ & 1.80 & 3 & 2.13 & 2 \\
\hline
\end{tabular}




\section{RASPRAVA I ZAKLJUČAK}

Mišljenja turističkih vodiča, lokalnih stručnjaka i vlasti te znanstvenika koj su dali svoje ocjene percipirane turističke zagušenosti u usporedbi s onima lokalnog stanovništva navode na zaključak da je Kashan na rubu prekoračenja prihvatnog kapaciteta, ali još nije dostigao fazu protivljenja temeljenu na modelu Doxeyjevog Irridexa. Za lokalo stanovništvo turistička zagušenost je prilika za razvoj i upoznavanje s ljudima iz drugih gradova i zemalja.

S obzirom na to da je Kashan bio mjesto spajanja komunikacijskih cesta i da je oduvijek bio domaćin trgovcima i putnicima, lokalno stanovništvo prihvatilo je gostoprimstvo i turističko domaćinstvo kao dijelove svoje kulture. Osim toga, istraživači su također percipirani kao gosti i turisti, a kulturna gostoljubivost bila je prisutna dok je lokalno stanovništvo odgovaralo na upitnike. Prisutnost istraživača dovela je do osjećaja ponosa lokalnog stanovništva zbog činjenice da su turisti odabrali Kashan kao svoje odredište. To može dovesti do činjenice da toleriraju masovnu prisutnost turista ili da to ne vide kao problem jer žele prisutnost i posjet turista iz svakog kutka zemlje ili svijeta.

Anketni upitnici distribuirani su i prikupljeni tijekom pred i post sezona. S obzirom na to da su razdoblja visoke potražnje bila tijekom proljetne sezone i praznika Nowruz, koji su prošli tijekom vremena prikupljanja podataka, te činjenice da je Kashan bio tranzitna ruta za mnoge gradove kao što su Isfahan i Yazd, turističku potražnju drugih destinacija također treba uzeti u obzir pri određivanju potražnje Kashana. Stanovnici grada imaju i druge stabilne karijere (neovisno o turizmu i turistima) kako bi osigurali životne potrebe. Činjenica da je vrijeme zagušenja vrijeme kada mještani rade ružinu vodu, tijekom golabgiri ceremonije, i činjenica da Kashanov turizam uglavnom ovisi o jednodnevnim izletima u okolna odredišta kao što je Gamsar, turisti posjećuju okolna odredi-

\section{DISCUSSION AND CONCLUSION}

Summarizing the opinions of tour guides, local experts and authorities, and academics considering the perceived congestion and comparing them with those of the local people, it can be concluded that Kashan is at carrying capacity threshold and has not reached the antagonism stage based on Doxey's Irridex Model. Tourist congestion for the locals is considered an opportunity for development and familiarization with people from other cities and countries.

Considering the fact that Kashan has been at the juncture of communication roads and has always been a host for merchants and travelers, local people have accepted hospitality and tourist hosting as parts of their culture. In addition, the researchers were also seen as guests and tourists, and the cultural hospitality was present while the locals responded to the questionnaires. The researchers' presence led to proud feelings among the locals that the tourists have chosen Kashan as their destination. This can lead to the fact that they tolerate the mass presence of the tourists or do not see it as a problem, since they desire the presence and visit of tourists from every corner of the country or the world.

The research questionnaires were distributed and collected during the low seasons. Considering that the high demand times have been during the spring season and Nowruz holiday, which had passed during the data collection time, and the fact that Kashan has been a transit road to many cities such as Isfahan and Yazd, the tourism demand of other destinations should also be considered in determining the Kashan's demand. The city residents have other stable careers (independent from tourism and tourists) to support their life. The fact that the congestion time is the time when the locals make rosewater, during Golabgiri ceremony, and the fact that Kashan's tourism is mainly dependent on one-day tours to its surrounding destinations such as Gamsar, the tourists 
šta rano tijekom dana i posjećuju Kashan u podne kada su stanovnici na svojim radnim mjestima, nemaju mnogo kontakta s turistima. Vlasti prisutne u uzorku stanovništva smatrane su mještanima i onima koji žive u gradu; odobrili su zagušenje koje je posljedica turizma i smatrali ga disruptivnim. Stoga odgovori mještana ne mogu u potpunosti odražavati njihova stajališta o zagušenju i njegovim nastalim problemima.

S druge strane, s obzirom na uvid turističkih vodiča, vlasti i stručnjaka u raznim aspektima turističkih usluga, uključujući prihvat, posluživanje, zagušenje znamenitosti i ostalim područjima, moguće je zaključiti da se njihovo kvalificirano mišljenje može generalizirati do razmjera ovog istraživanja. Na osnovi prikupljenih mišljenja dvaju statističkih skupina, znanstvenika i lokalnih stručnjaka, usluga marketinškog spleta analizirana je prema 7P sa zaključkom da su obje skupine na prva dva mjesta postavile osoblje i cijenu, unatoč njihovim različitim mišljenjima o strategijama demarketinga u Kashanu. Nakon osoblja i cijene, prioritet za lokalne vlasti bili su promocija i proces, fizički dokaz, proizvod, sve do najnižeg, distribucije, s prosjekom 2,33.

Znanstvenici su dali prednost drugim elementima, poput distribucije, promocije, procesa i proizvoda, dok je fizički dokaz završio na dnu ljestvice. Uzevši u obzir rezultate skupina stručnjaka i znanstvenika, može se zaključiti da osoblje (ljudski resursi) i cijena imaju najveći utjecaj na turističku potražnju pa stoga i na upravljanje turističkom potražnjom. Ovo je ispitivanje prvo koje pokazuje da je kadrovska strategija prioritetna za stručnjake i znanstvenike te se stoga ne može uspoređivati s drugima u ovom području. McLean, Havitz i Adkins (2002) tvrde da svi elementi marketinškog spleta mogu utjecati na demarketing. Medway, Warnaby i Dharni (2010) navode da, budući da se sve strategije demarketinga mogu rabiti istovremeno, mogu imati smisla te da nije ispravno odabirati ih po prioritetu. Ipak, McLean, visit the surrounding destinations early in the days and visit Kashan at noon when the residents are in their workplaces, they do not have much contact with the tourists. The authorities present in the sample population were considered as the locals and those who live in the city; they approved the congestion resulted from the tourism and considered it disruptive. Therefore, the responses of the locals cannot completely reflect their views concerning congestion and its resultant problems.

On the other hand, considering the oversight of the tourism guides, authorities, and experts on different aspects of tourist reception, catering, site congestion, and related areas, it can be concluded that their opinion as qualified people can be generalized to the scope of the present study.

After collecting the opinions of two statistical groups, the academics and local experts, the marketing mix service was analyzed under the 7Ps marketing mix. To this end, both authorities in Kashan and academics believe that the 'personnel' and 'price' elements stand first and second, despite their different opinions on demarketing strategies in Kashan. After the 'personnel' and 'price', the priorities for the authorities were from 'promotion', 'process', 'physical evidence', 'product', to the lowest one, 'distribution' with an average of 2.33 .

Academics prioritized the other elements as 'distribution', 'promotion' 'process', and 'product' and 'physical evidence' occupied the lowest rank. Considering both groups of experts and academics, it can be concluded that 'personnel' (human resources) and 'price' have the highest influence on tourist demand and in consequence tourists demand management. This study is the first one to show that personnel strategy is a priority by the experts and the academics, so it cannot be compared with the other ones in this area. McLean, Havitz and Adkins (2002) believed that all the elements of marketing mix could impact demarketing. Medway, Warnaby and Dharni (2010) expressed that since all demarketing strategies could be used simultane- 
Havitz i Adkins (2002) su uvažili da cijena može više utjecati na potrošače s niskim prihodima nego na ostale.

Uzimajući u obzir potkategorije svakog elementa demarketinga u Kashanu, studija pokazuje da su tri prioriteta u slučaju osoblja (kao prvog skupa prioriteta) bila u cilju suradnje osoblja u različitim sektorima radi upravljanja potražnjom, korištenja osoblja s nepunim radnim vremenom i obrazovanja osoblja za učinkovitu provedbu strateških elemenata povezanih s cijenom (kao drugi skup prioriteta), poput povećavanja cijena ulaznica za atrakcije, besplatne posjete izvan glavne sezone za one atrakcije koje nemaju besplatan ulaz u vršnoj sezoni te povećanja cijena za dodatno korištenje objekata (prioriteti su prikazani u Tablici 6).

$\mathrm{S}$ obzirom na praktične posljedice za vlasti Kashana, znajući da osoblje ima prioritet kao najvažnija strategija, njihovo obrazovanje može dovesti do upravljanja turističkom potražnjom. Ova edukacija može se provesti kako bi se turiste usmjeravalo na druga manje prometna mjesta te upravljalo vremenom posjeta mjestu bez posljedica na imidž destinacije i zadovoljstvo turista. Također se mogu održavati treninzi osoblja u odgovarajućem interaktivnom ophođenju s turistima, temeljenom na održivom razvoju. Nijedan kupac nije štetniji za ugled tvrtke od onoga koji doživi da su mu osjećaji ismijani. Demarketing se stalno provodi, čak i bez svijesti kupaca. Stoga bi kupce koji podliježu demarketingu trebalo oprezno uvažavati. Njihovo nezadovoljstvo zbog nemogućnosti pristupa znamenitostima može se značajno smanjiti upravljanjem linija čekanja i ponudom alternativnih aktivnosti i znamenitosti ili drugim strategijama demarketinga od strane obučenog osoblja. Dodatne mjere mogu uključivati i povećanje cijena ulaznica u vršnim sezonama i smanjenje ili ukidanje naknada izvan sezone.

Za osmišljavanje strategija kojima se mijenjaju mišljenja, stavovi i potom očekivanja ljudi može se upotrijebiti Ajzenova teorija ously, they can be meaningful when standing together, and their prioritizing is not correct. McLean, Havitz and Adkins (2002), however, acknowledged that price can influence low-income consumers more than the others.

Considering the sub-categories of each demarketing element in Kashan, the study shows that the three priorities in case of the personnel (as the first set of priorities) were in order the cooperation of personnel in different sectors to manage the demand, the use of part-time personnel, and personnel education to effectively implement 'price' related strategy elements (as the second set of priority) such as increasing visit fees for sites, making low-season visiting free of charge, for sites which are not free during high-season, and increasing fees for extra facility uses (the priorities are shown in Table 6).

Considering practical implications for Kashan authorities, since the 'personnel' was prioritized as the most important strategy, their education can lead to tourism demand management. This education can be done to appropriately guide the tourists in visiting other less crowded sites and to manage the visit time in a site without damaging the destination image and satisfaction of the tourists. Personnel training sessions can also be held to help them acquire appropriate interactive behavior with the tourists, based on sustainable development. No customer is more harmful to the reputation of the company than the one who thinks their feelings have been mocked. Demarketing is constantly done, even without the awareness of the customers. Therefore, those customers that are subject to demarketing should be considered carefully. Through managing waiting lines by trained personnel, offering alternative activities and sites, dissatisfaction resulted from lack of access to some sites or other demarketing strategies can significantly be reduced. Also, increasing the entrance fee in high seasons and reducing or removing fees during low seasons are among the issues that should be implemented. 
planiranog ponašanja. Zbog toga, turiste treba informirati o svim pristupima demarketinga na djelu u Kashanu prije no što odluče posjetiti ga. Strategija promocije popraćena ostalim strategijama može smanjiti potražnju prije puta. Upravljanjem čekanja ljudi i predlaganjem drugih aktivnosti i alternativnih destinacija, uz ostale strategije demarketinga, može se smanjiti nezadovoljstvo izazvano uskraćivanjem dozvole posjeta nekim znamenitostima. Osim smanjenja turističke potražnje prije putovanja, također je potrebno planirati inicijative turističke redistribucije i potaknuti posjete kako bi se uz smanjenje ukupnog volumena turističke potražnje u Kashanu preusmjerio volumen dolaska turista na manje posjećene znamenitosti (npr. džamija i medresa Agha Bozorg Mosque i Tepe Sialk). Sezonalnost se također može iskorisiti za organiziranje putovanja u podsezoni i tako pomoći turizmu ovoga grada.

Opći zaključak studije pokazuje da, budući da se mnoge rekreativne destinacije suočavaju s ograničenjima pristupa za sve posjetitelje tijekom dana velike potražnje, posebno u slučajevima rijetkih rekreativnih resursa koji mogu dovesti do negativnih posljedica i za posjetitelje i za destinaciju, većina istraživača vjeruje da je jedan od najčešćih učinaka povećanja posjetitelja zagušenje koje može negativno utjecati na turiste, lokalno stanovništvo i znamenitost. Stoga bi marketinški stučnjaci trebali koristiti postojeće strategije demarketinga za upravljanje odredištem, posebno tijekom vremena velike potražnje.

Koristeći literaturu, prikupljene su i istražene strategije demarketinga destinacije Kashan. Drugi istraživači i marketinški stručnjaci mogu istražiti ove strategije u drugim turističkim destinacijama koje se suočavaju sa zagušenjem, na temelju jedinstvenih svojstava svake lokacije na koju se rezultati ove studije ne mogu generalizirati. U ovoj studiji postojala su određena ograničenja kao što su mjerenje razine zagušenja s gledišta turista te mjerenje percipirane razine zaguše-
Ajzen's theory of planned behavior can be utilized to devise strategies to change people's beliefs, attitudes, and later their expectations. Therefore, the tourists should be informed about all demarketing approaches used in Kashan beforehand while deciding on the visit. By accompanying the "promotion' strategy with other strategies, demand can be reduced before the travel. Through managing waiting people and proposing suggestions on activities and alternative destinations, along with other demarketing strategies, dissatisfaction created from disallowance from some site entrances can be reduced. Next to reducing the tourism demand before the travel, initiatives should be planned for tourist redistribution and accelerate of visiting process so that alongside reduction in the whole volume of tourist demand in Kashan, the tourist entrance volume can be redistributed in less-visited sites (e.g., Agha Bozorg Mosque and School and Tepe Sialk). Also, arranging tours in low-season periods can be modified seasonally and help the tourism industry of the city.

The general conclusion of the study shows that since many recreational destinations face limitations of access for all visitors during the days of high demand, particularly in cases of rare recreational resources that can lead to negative consequences for both visitors and the destination, the majority of researchers believe that one of the most common effects of visitor increase is congestion that can negatively impact the tourists, local people, and the site. Therefore, the marketers should use the present demarketing strategies to manage the destination, especially during the high demand times.

Using the literature, demarketing strategies of the destination, Kashan, were collected and investigated. Other researchers and marketers can investigate these strategies in other tourist destinations that face congestion, based on the unique properties of each site to which the findings of this study cannot be generalized. In this study, there were some limitations such as the measurement of 
nja od strane lokalnog stanovništva u sezonama velike potražnje. Razlikovanje poželjnih i nepoželjnih posjetitelja i određivanje koji je posjetitelj u poželjnoj ili nepoželjnoj skupini zahtijeva sveobuhvatnu studiju na kojoj drugi istraživači mogu raditi. Jedna od posljedica prekomjerne potražnje ili zagušenja je uništavanje povijesnih zgrada ili okoliša, tako da studije o određivanju količine (fizičke) tolerancije mjesta mogu biti vrlo praktične $u$ kontekstu demarketinga.

\section{LITERATURA - REFERENCES}

Armstrong, E. K., Kern, C. L. (2011). De-marketing manages visitor demand in the Blue Mountains National Park. Journal of Ecotourism, Vol. 10, No. 1, pp. 21-37. DOI: https://doi. org/10.1080/14724040903427393

Azzam, Z. (2019). De-marketing as a strategic tool for managing customer excessive demand within the shortage of environmental recourses of water: empirical study in Jordan. Global Journal of Economics and Business, Vol. 7, No. 1, pp. 105-119. DOI: https://doi.org/10.31559/GJEB2019.7.1.8

Baum, T., Lundtorp, S. (2001). Seasonality in Tourism. Routledge. DOI: https://doi. org/10.4324/9780080516806

Beeton, S. (2002). Recapitalizing the image: Demarketing undesired film-induced tourism. In Proceedings of TTRA 33rd Annual Conference: Recapitalizing on Tourism Research. Arlington, Virginia, USA.

Beeton, S. (2003). Swimming against the tide - integrating marketing with environmental management via demarketing [online], Braithwaite, R. L. (ed.). CAU- THE 2003: Riding the Wave of Tourism and Hospitality Research. Lismore, N. S. W.: Southern Cross University.

Beeton, S. (2006). Sustainable tourism in practice: Trails and tourism. Critical mana- congestion level from tourists' view, the measurement of the perceived level of congestion by the locals in high demand seasons. Differentiating between desirable and undesirable visitors and designating which visitor is in a desirable or an undesirable group requires a comprehensive study that other researchers can work on. One of the consequences of excessive demand or congestion is the destruction of historical buildings or the environment, so studies on determining the amount of (physical) tolerance capacity of a site can be greatly practical concerning demarketing.

gement issues of multi-use trails, Tourism and Hospitality Planning \& Development, Vol. 3, No. 1, pp. 47-64. DOI: https:// doi.org/10.1080/14790530600727227

Beeton, S., Benfield, R. W. (2002). Demand control: The case for de-marketing as a visitor and environmental management tool. Journal of Sustainable Tourism, Vol. 10, No. 6, pp. 479 -513. DOI: https://doi. org/10.1080/09669580208667184

Beeton, S., Pinge, I. (2003). Casting the holiday dice: Demarketing gambling to encourage local tourism. Current Issues in Tourism, Vol. 6, No. 4, pp. 309-322. DOI: https:// doi.org/10.1080/13683500308667958

Beeton, S., Travel and Tourism Research Association. (2001). Cyclops and sirens Demarketing as a proactive response to negative consequences of one-eyed competitive marketing.

Benfield, R. W. (2000). Good things come to those who wait: Demarketing Sissinghurst Castle Garden, Kent for sustainable mass tourism. In TTRA Annual Conference Proceedings (pp. 226-234). Boulder, CO: Travel and Tourism Research.

Benfield, R. W. (2001). Turning back the hordes: Demarketing as a means of managing mass tourism. In TTRA Conference Proceedings.

Benfield, R. W. (2010). Good things come to those who wait: Sustainable tourism and 
timed entry at Sissinghurst Castle Garden, Kent. Tourism Geographies, Vol. 3, No. 2, pp. 207-217. DOI: https://doi. org/10.1080/14616680010030275

Booms, B. H., Bitner, M. J. (1981). Marketing strategies and organization structures for service firms. Marketing of services, pp. 47-51.

Bradley, N., Blythe, J. (2014). Demarketing and Marketing. N. Bradley \& J. Blythe içinde, Demarketing, pp. 212-217.

Chaudhry, P., Cesareo, L., Pastore, A. (2019). Resolving the jeopardies of consumer demand: Revisiting demarketing concepts, Vol. 62, No. 5, pp. 663-677. Business Horizons, Vol. 62. DOI: https://doi. org/10.1016/j.bushor.2019.05.002

Clements M. A. (1989). Selecting tourist traffic by Demarketing. Tourism management, Vol. 10, No. 2, pp. 89-94. DOI: https://doi. org/10.1016/0261-5177(89)90048-4

Clements,M.(1998).Planningtotourismcapacity in a crisis. Journal of Travel Research, Vol. 37, No. 1, pp. 56-62. DOI: https://doi. org/10.1177/004728759803700107

Dadzie, K. Q. (1989). Demarketing strategy in shortage marketing environment. Journal of the Academy of Marketing Science, Vol. 17, No. 2, pp. 157-165. DOI: https:// doi.org/10.1007/BF02723374

Drugova, T., Kim, M-K., Jakus, P. (2020). Marketing, Congestion, and Demarketing in Utah's National Parks. Tourism Economics. DOI: https://doi. org/10.1177/1354816620939722

Eliasson, E., Velasco, K. (2018). Coping with over tourism: redirecting tourism consumption through social media and the internet. Master degree project in marketing and consumption. University of Gothenburg, School of business, economics and law.

Fullerton, L., McGettigan, K., Stephens, S. (2010). Integrating management and marketing strategies at heritage sites. International Journal of Culture, Tourism and Hospitality Research, Vol.
4, No. 2, pp. 108-117. DOI: https://doi org/10.1108/17506181011045181

Gallagher, K. (1994). The use of habit-change strategies in demarketing - reducing excessive discretionary consumption. Unpublished PhD Thesis. University of British Columbia.

Gerstner, E., Hess, J., Chu, W. (1993). Demarketing as a differentiation strategy. Marketing Letters, Vol. 4, pp. 49-57. DOI: https://doi.org/10.1007/BF00994187

Groff, C. (1998). Demarketing in park and recreation management. Managing Leisure, Vol. 3, No. 3, pp. 128-135. DOI: https://doi. org/10.1080/136067198376030

Hall, C. M., Wood, K. J. (2021). Demarketing Tourism for Sustainability: Degrowing Tourism or Toving the Teckchairs on the Titanic? Sustainability, Vol. 13, No. 3, 1585. DOI: https://doi.org/10.3390/ su13031585

Kern, C. L. (2006). Demarketing as a tool for managing visitor demand in national parks - An Australian case study. Master's Thesis. University of Canberra.

Kotler, P. (1973). The major tasks of marketing management. Journal of Marketing, Vol. 37, No. 4, pp. 42-49. DOI: https:// doi.org/10.1177/002224297303700407 \& https://doi.org/10.2307/1250357

Kotler, P., Levy, S. J. (1971). Demarketing, yes, demarketing. Harvard Business Review, Vol. 49, No. 6, pp. 74-80.

Krajnović, A., Raguž, I., Gortan-Carlin, I. (2020). Strategic management and demarketing in UNESCO WHSs: a comparative analysis of two Croatian tourist destinations. Bulletin of Geography, Socio-economic Series, No. 48, pp. 113-128. DOI: https://doi.org/10.2478/bog-2020-0016

Kumar, G. M. K., Srivastav, A. K. (2019). Sustainable tourism marketing in Andaman and Nicobar Islands. International Journal of Scientific Research and Review, Vol. 7, No. 3, pp. 663-671. DOI: http://doi. org/10.13140/RG.2.2.34215.91047 
Kwok, L., Tang, Y., Yu, B. (2020). The 7 Ps marketing mix of home-sharing services: Mining travelers' online reviews on Airbnb. International Journal of Hospitality Management, Vol. 90. DOI: https:// doi.org/10.1016/j.ijhm.2020.102616

Magalhães, M., Tenreiro de Magalhaes, S., Rodrigues, C., Marques, S. (2017). Acceptance criteria in a Promotional Tourism Demarketing Plan. Procedia Computer Science, Vol. 121, pp. 934-939. DOI: https://doi.org/10.1016/j. procs.2017.11.121

McLean, D. J., Havitz, M. E., Adkins K. D. (2002). Demarketing Leisure Services: The Case of Municipal Golf Courses. Journal of Park and Recreation Administration, Vol. 20, No. 2, pp. 90-110.

Medway, D., Warnaby, G. (2008). Alternative perspectives on marketing and the place brand. European Journal of Marketing, Vol.42,No.5-6,pp. 641-653. DOI: https:// doi.org/10.1108/03090560810862552

Medway, D., Warnaby, G., Dharni, S. (2010). Demarketing places: Rationales and strategies. Journal of Marketing Management, Vol. 27, No.1-2,pp. 124-142. https:// doi.org/10.1080/02672571003719096

Murzyn-Kupisz, M., Hołuj, D. (2020). Museums and Coping with Overtourism. Sustainability, Vol. 12, No. 5, 2054. DOI: https://doi.org/10.3390/su12052054

Nared, J., Razpotnik Visković, N. (2014). Managing Cultural Heritage Sites in Southeastern Europe. DOI: https://doi. org/10.3986/9789610503675

Olokesusi, F., Agboola, O., Aina, C., Ajayi, O. (2019). Evolution of Demarketing in the Tourism Industry and Implications for Sustainability. International Journal of Innovative Science and Research Technology, Vol. 4, No. 10, pp. 625-630.

Othman, B., Harun, A., Rashid, W., Nazeer, S., Bin, A., Ghaffar, K. (2019). The influences of service marketing mix on customer loyalty towards Umrah travel agents: Evidence from Malaysia. Management Science Letters, Vol. 9, pp. 865-876. DOI: https://doi.org/10.5267/j. msl.2019.3.002

Pandey, B., Ritthichairoek, A., Puntien, S. (2020). Examination of marketing mix factors in Chinese Tourists' Demand for Spa Service in Middle-sized Bangkok Hotels. $11^{\text {th }}$ International Academic Conference "Global Goals, Local Actions: Looking Back and Moving Forward.pp. 103-111.

Peeters, P., Gössling, S., Klijs, J., Milano, C., Novelli, M., Dijkmans, C., Eijgelaar, E., Hartman, S., Heslinga, J., Isaac, R., et al. (2018). Research for TRAN Committee-Overtourism: Impact and Possible Policy Responses; European Parliament, Policy Department for Structural and Cohesion Policies. Brussels: Belgium. available at: https://www.europarl.europa. eu/RegData/etudes/STUD/2018/629184/ IPOL_STU(2018)62184_EN.pdf (accessed on 15 October 2019)

Sadiki, F. A. (2012). Sustainable Tourism Marketing Strategies at UNESCO World Heritage Sites. UNLV Theses, Dissertations, Professional Papers, and Capstones. 1477. available at: https://digitalscholarship.unlv.edu/thesesdissertations/1477

Soliman, D. (2010). Managing Visitors Via Demarketing in The Egyptian World Heritage Site: Giza Pyramids. Journal of Association of Arab Universities for Tourism and Hospitality, Vol. 7, No. 1, pp. 15-20.

Suh, M., Rho T., Greene, H. (2012). Relationship behavior between customers and service providers in demarketing situations: What makes customers try to improve their relationships? Database Marketing \& Customer Strategy Management, Vol. 19, No. 1, pp. 39-55. DOI: https://doi.org/10.1057/dbm.2012.3

Theobald, W. F. (2005). Global tourism. Routledge. 
UNWTO (2007). A Practical Guide to Tourism Destination Management. UNWTO.

Watts, J. (2018). We have 12 years to limit climate change catastrophe, warns UN. available at: https://www.theguardian.com

Wearing, S., Archer D., Beeton S. (2007). The sustainable marketing of tourism in protected areas: moving forward. The sustainable corporative tourism research center (SCTRC).

Wearing, S., Archer, D. (2005). Developing an approach to marketing and demarketing of tourism for protected area management. In J. Senior (Ed.). Parks and Leisure Australia national conference: Current issues: Future challenges. Tasmania, 9-13 October.

Wearing, S., Neil, J. (1999). Ecotourism: impacts, potentials and possibilities. Butterworth-Heinemann, Oxford.

Wearing, S., Schweinsberg, S., Tower, J. (2016). Marketing national parks for sustainable tourism. Bristol: Channel View Publications. DOI: https://doi. org/10.21832/9781845415594

Wearing, S., Schweinsberg, S., Tower, J. (2016). Marketing national parks for sustainable tourism. Bristor: Channel View Publications.
Weiler, B., Moyle, B., Scherrer, P., Hill, M. (2018). Demarketing an iconic national park experience: Receptiveness of past, current and potential visitors to selected strategies. Journal of Outdoor Recreation and Tourism, Vol. 25, pp. 122-131. DOI: https://doi.org/10.1016/j. jort.2018.06.001

Whitelaw, P A., King, B. E. M., Tolkach, D. (2014). Protected areas, conservation and tourism - financing the sustainable dream. Journal of Sustainable Tourism, Vol. 22, No. 4. pp. 584-603. DOI: https://doi. org/10.1080/09669582.2013.873445

Primljeno: 9. siječnja 2021. /

Submitted: 9 January 2021

Prihvaćeno: 6. listopada 2021. I

Accepted: 6 October 2021

Ovaj je rad izdan pod licencom CC BY-NC (http://creativecommons.org/licenses/bync/4.0/).

This is an open access article under the CC BY-NC license (http://creativecommons.org/ licenses/by-nc/4.0/). 